\title{
High Ice Water Concentrations in the 19 August 2015 Coastal Mesoconvective System
}

\author{
Fred H. Proctor ${ }^{\dagger}$ and Steven Harrah \\ NASA Langley Research Center, Hampton, VA, 23681-2199 \\ George F. Switzer, ${ }^{\S}$ Justin K. Strickland, ${ }^{* *}$ and Patricia J. Hunt ${ }^{* *}$ \\ Analytical Mechanics Associates, Inc., Hampton, VA, 23681-2199
}

\begin{abstract}
During August 2015, NASA's DC-8 research aircraft was flown into High Ice Water Content (HIWC) events as part of a three-week campaign to collect airborne radar data and to obtain measurements from microphysical probes. Goals for this flight campaign included improved characterization of HIWC events, especially from an airborne radar perspective. This paper focuses on one of the flight days, in which a coastal mesoscale convective system (MCS) was investigated for HIWC conditions. The system appears to have been maintained by bands of convection flowing in from the Gulf of Mexico. These convective bands were capped by a large cloud canopy, which masks the underlying structure if viewed from an infrared sensing satellite. The DC-8 was equipped with an IsoKinetic Probe that measured ice concentrations of up to $2.3 \mathrm{~g} \mathrm{~m}^{-3}$ within the cloud canopy of this system. Sustained measurements of ice crystals with concentrations exceeding $1 \mathrm{~g} \mathrm{~m}^{-3}$ were encountered for up to ten minutes of flight time. Airborne Radar reflectivity factors were found to be weak within these regions of high ice water concentrations, suggesting that Radar detection of HIWC would be a challenging endeavor. This case is then investigated using a three-dimensional numerical cloud model. Profiles of ice water concentrations and radar reflectivity factor demonstrate similar magnitudes and scales between the flight measurements and model simulation. Also discussed are recent modifications to the numerical model's ice-microphysics that are based on measurements during the flight campaign. The numerical model and its updated ice-microphysics are further validated with a simulation of a well-known case of a supercell hailstorm measured during the Cooperative Convective Precipitation Experiment. Differences in HIWC between the continental supercell and the coastal MCS are discussed.
\end{abstract}

\section{Nomenclature}

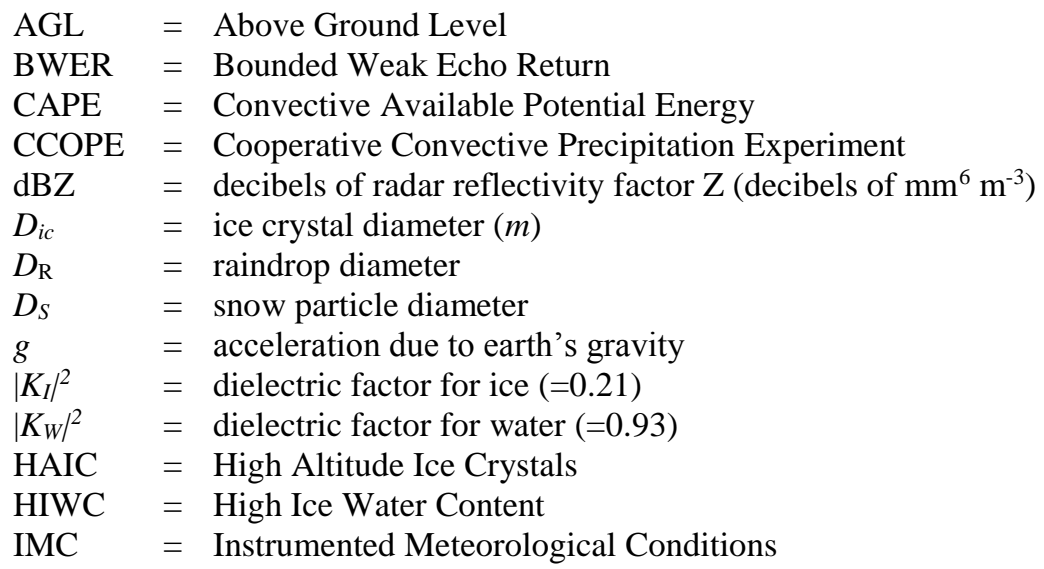

\footnotetext{
† Senior Research Scientist, Electromagnetics \& Sensors Branch, MS 490, AIAA Senior Member

* Radar Technical Lead, Electromagnetics \& Sensors Branch, MS 490

$\S$ NASA Contractor, Electromagnetics \& Sensors Branch, MS 490, AIAA Senior Member

** NASA Contractor, Electromagnetics \& Sensors Branch, MS 490
} 


$\begin{array}{ll}\text { IWC } & =\text { ice water concentration }\left(\mathrm{g} / \mathrm{m}^{3}\right) \\ \mathrm{MCS} & =\text { Mesoscale Convection System }(\text { same as Mesoconvective Systems) } \\ M_{R} & =\text { mass water content for rain water }\left(\mathrm{g} / \mathrm{m}^{3}\right) \\ M_{S} & =\text { mass water content for snow water }\left(\mathrm{g} / \mathrm{m}^{3}\right) \\ \mathrm{MSL} & =\text { Mean Sea Level } \\ N\left(D_{R}\right) & =\text { number of raindrops per unit diameter } D_{R} \text { per unit volume } \\ N\left(D_{S}\right) & =\text { number of snow particles per unit diameter } D_{S} \text { per unit volume } \\ N_{O H} & =\text { intercept value in hail/graupel particle size distribution }\left(\mathrm{m}^{-4}\right) \\ N_{O R} & =\text { intercept value in raindrop size distribution }\left(\mathrm{m}^{-4}\right) \\ N_{O S} & =\text { intercept value in snow particle size distribution }\left(\mathrm{m}^{-4}\right) \\ R R F & =\text { Radar Reflectivity Factor } \\ t & =\text { time coordinate } \\ \mathrm{TASS} & =\text { Terminal Area Simulation System } \\ T_{C} & =\text { temperature }(\text { Centigrade) } \\ x, y & =\text { orthogonal space coordinates in lateral plane } \\ V & =\text { horizontal component of velocity in y direction } \\ \mathrm{Z} & =\text { vertical coordinate, elevation } \\ Z_{R} & =\text { radar reflectivity factor from rain } \\ \mathrm{Z}_{\mathrm{S}} & =\text { radar reflectivity factor from snow } \\ \delta_{\mathrm{S}} & =\text { snow particle density }\left(\mathrm{kg} \mathrm{m}^{-3}\right) \\ \delta_{\mathrm{W}} & =\text { specific density of water }\left(\mathrm{kg} \mathrm{m}^{-3}\right)\end{array}$

\section{Introduction}

$\mathrm{T}$

HE occurrence of high-concentrations of ice crystals within the upper-regions of large convective systems can threaten the safety of commuter and large-transport jet aircraft. The ingestion of ice crystals into jet engines at large concentrations has caused uncommanded power loss, including engine flameout, rollback, vibration, and engine damage. ${ }^{1,2}$ Over one hundred and sixty of these engine icing incidents have been reported since the mid-1990s, ${ }^{3}$ and roughly ten incidents continue to occur internationally per year. In most cases, pilots have been able to restart their engines and regain sufficient power once they have escaped the area of threat, although sometimes with a significant loss in altitude. So far, no known casualties or losses of aircraft have been attributed to engine icing events. Another threat from ice-crystal encounters, is the obstruction of the aircraft's Pitot tube, which can cause erroneous measurements of airspeed. Incorrect sensing of airspeed could lead to dangerous actions from either the pilot or the aircraft's automated flight systems. Similarly, anomalous readings also have been reported by the aircraft's total air temperature (TAT) probes, which provides temperature data for aircraft functions such as de-icing systems. Typical weather conditions during engine icing events and ice-crystal induced Pitot anomalies are: subfreezing temperatures, low visibility, low to moderate turbulence, absence of significant airframe icing, TAT anomalies, static charging, and weak or no detectable radar reflectivity at flight level.

Due to the international concern for air safety, the detection and characterization of regions with dense ice-crystal concentrations have been under investigation by international consortiums of airframe manufactures, radar and engine manufactures, government rule making and flight operations organizations, weather and aeronautical research organizations, and academia. These consortiums have termed the threat of high ice-water concentrations, as either High Ice Water Content ${ }^{4}$ (HIWC) or High Altitude Ice Crystals ${ }^{5,6,7}$ (HAIC). The European-led consortiums prefer to use HAIC, to identify the aviation-hazard due to ice crystals, but both acronyms are synonymous for identifying the threat.

Weather systems often associated with HIWC encounters that lead to engine icing events are large, long-lasting convective systems known as Mesoscale Convective Systems ${ }^{8}$ (MCS) (e.g., Fig. 1). Engine icing incidents also have occurred in the upper-levels of tropical storms as well. ${ }^{1}$ Both types of systems are usually routed in oceanic or deep moist environments that have moderate convective instability. Because of the characteristic size and duration of these weather systems, ${ }^{9}$ they can inject large concentrations of ice crystals into regions near cruise altitudes. ${ }^{10}$ Aircraft incidents due to HIWC are most likely to occur with prolonged flight paths through the cloud canopies of these systems. ${ }^{3}$ Radar reflectivity factor sensed from the airborne radar usually appears innocuous due to the absence of larger-sized ice particles. Incidents due to engine icing seem less reported for flights through the anvil canopies of supercells $^{11}$ and other strong continental storms, possibly due to the routine avoidance of these systems by air traffic. ${ }^{2}$ These stronger continental storms will possess higher radar reflectivity, even at cruise level, due to hail, graupel, and larger ice particles that are carried upward within strong updrafts.

American Institute of Aeronautics and Astronautics 


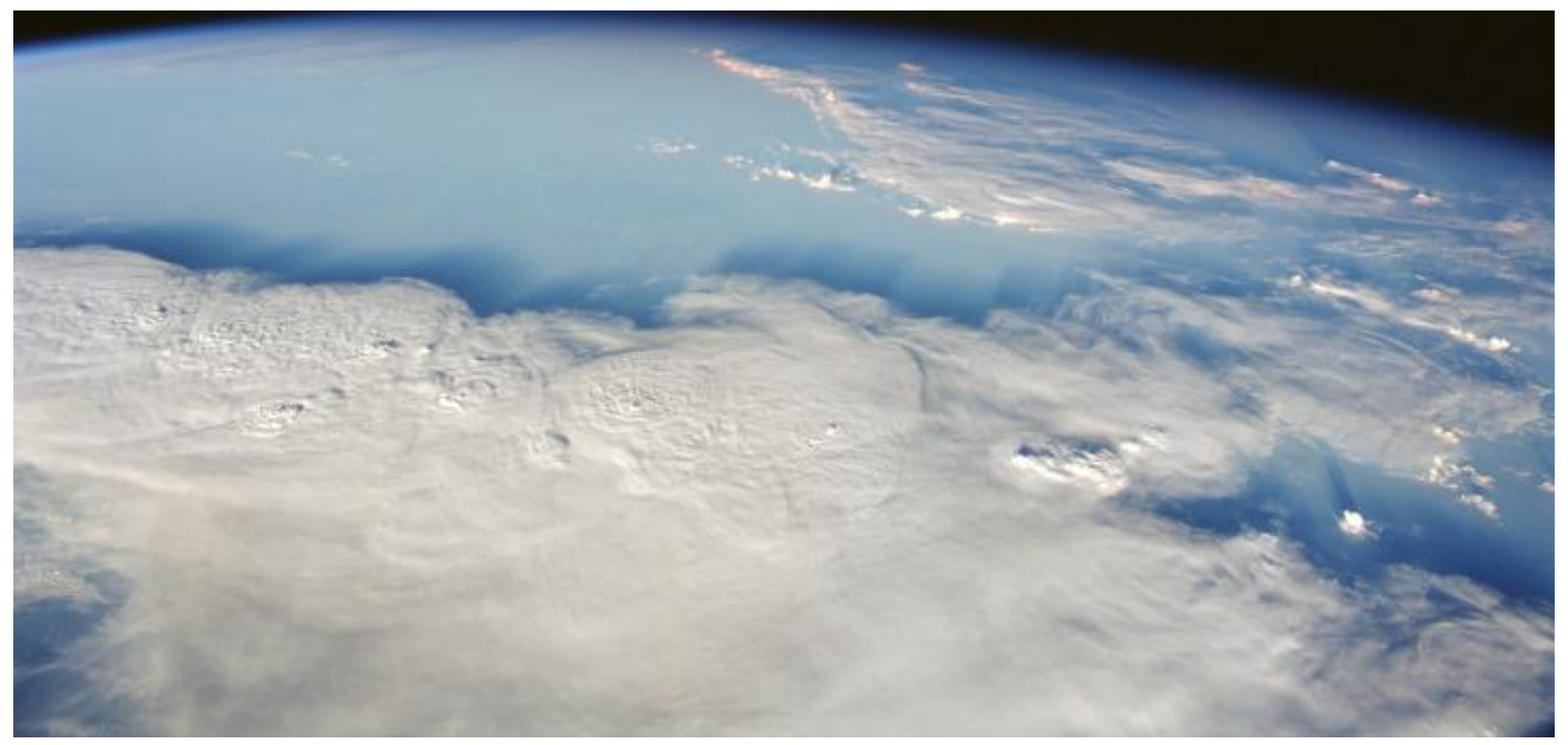

Figure 1. Mesoscale Convective System viewed from International Space Station (NASA). Overshooting tops identify the presences of updraft plumes that feed ice crystals into the spreading cloud canopy.

The threat of ice crystals on engine performance is dependent upon the ice crystal concentration and the duration of exposure. The actual threshold and duration necessary to induce engine power loss also may vary by engine design and use. ${ }^{1}$ Brief encounters with heavy concentrations may have little impact on engine performance compared to prolonged exposure to moderate concentrations. The certification standard for engine exposure to supercooled liquid water is $2 \mathrm{~g} \mathrm{~m}^{-3}$ for an exposure time of $10 \mathrm{~min} .{ }^{12}$ However, ice crystals may be more efficient than supercooled water in reducing the temperature of the engine's internal surfaces since extra heat is absorbed by the melting of the crystals. Engine experts have suggested that an exposure to concentrations greater than about $1 \mathrm{~g} \mathrm{~m}^{-3}$ for an extended period of time (or distance) may be sufficient to induce engine icing and power loss.

Since ice water concentration is not routinely measured and is difficult to diagnose accurately from other variables, flight data is almost nonexistent for understanding relationships between ice water concentration and engine power loss. However, in one incident reported by Mason $e t ~ a l,{ }^{1}$ an engine rollback occurred during a microphysical research flight; and therefore, the power loss could be compared to the actual ice water measurement. This flight was within the low-reflectivity region downwind of a continental cumulonimbus and was exposed to ice crystals for a prolonged period. The measured ice water content peaked at $1.1 \mathrm{~g} \mathrm{~m}^{-3}$ and the 47 min average proceeding engine rollback was reported as $0.7 \mathrm{~g} \mathrm{~m}^{-3}$. Further research is needed to define the appropriate thresholds and duration of exposure that represent the hazard due to engine icing.

\section{August 2015 HIWC Radar Flight Campaign}

NASA, along with partners including the Federal Aviation Administration (FAA), Boeing Aircraft, National Center for Atmospheric Research (NCAR), Met Analytics and Science Engineering Associates conducted a flight campaign in August 2015 to investigate the ability of airborne weather radar to detect high concentrations of ice crystals, and to discern potentially hazardous conditions from the more benign, low concentration that often exist. The flight campaign was conducted out of Fort Lauderdale, Florida, using NASA-Armstrong's DC-8 Airborne Science Laboratory. The research aircraft was equipped with NASA-Glenn meteorological probes and NASA-Langley's research radar. The radar, a modified Honeywell RDR-4000, X-band Doppler with an antenna of 4-degree beam width, was installed within the nose of the DC- 8 for the flight campaign. The aircraft also included equipment to measure, airspeed (Pitot tube) and total air temperature (TAT probe), as well as cloud characterization instrumentation that included: second-generation IsoKinetic Probe ${ }^{13,14}$ (IKP-2) and a Robust Ice Crystal Detector (ICD) ${ }^{15}$ for measuring ice water content. Other equipment included hot-wire probes to measure water content, and multiple sensors to measure cloud and precipitation particle size distributions (precipitation imaging probe - PIP; optical imaging 2D-S, and a cloud droplet probe-CDP) (Fig. 2). The primary intent of this flight campaign was to further characterize

American Institute of Aeronautics and Astronautics 
HIWC conditions and to investigating relationships between radar reflectivity factor, ice water content, and particle size distributions.

Weather information for supporting the missions was obtained from visible and infrared satellites, weather station observations, ground-based weather radar, and predictions from numerical weather forecast models. Analysis of this data was used to recommend time of take-off, and to guide the DC-8 into potential regions with high-concentrations of ice crystals.

Ten research flights over a 20-day period were launched from Ft. Lauderdale into MCS and tropical systems. Locations of these weather systems were over the Atlantic Ocean, the Caribbean Sea, and the Gulf of Mexico (Fig. 3). Measurements during the flights were mostly over water, but sometimes over inland coastal regions. The DC-8 flights traversed the cloud canopies of the MCS and tropical storm convection at various elevations where ice crystals were likely to be present. Most of the data were collected at altitudes where the temperatures were colder than $-25^{\circ} C$. For safety, the most convectively-active regions of the storms were circumvented, including regions with active lightning and with flight-level radar reflectivity greater than $40 \mathrm{dBZ}$. These criteria likely precluded measurements in areas with the highest ice concentrations, but these areas are usually avoided by commercial air traffic. The DC- 8 used engine throttling techniques to suppress any onset of engine icing during ice crystal encounters. No engine power-loss was recorded during any of the flights.

The flight campaign collected over 27 flight-hours $(19,600 \mathrm{~km})$ of in-cloud data, including long-duration exposures to ice water concentrations greater than $1 \mathrm{~g} \mathrm{~m}^{-3}$. For each of the flight days, the peak measured ice water concentration (IWC) was greater than $2 \mathrm{~g} \mathrm{~m}^{-3}$, and the peak radar reflectivity factor (RRF) measured directly in front of the aircraft ${ }^{\dagger \dagger}$ was $32 \mathrm{dBZ}$ or less (Table 1). The flights through the tropical storms measured greater concentrations of ice crystal water and at longer duration, than with the flights through the oceanic and coastal MCS storms. Otherwise, the ice particle distributions and the correlation between ice water content and radar reflectivity factor appeared to be similar between each day. The peak measured IWC was $3.2 \mathrm{~g} \mathrm{~m}^{-3}$ during a flight through tropical storm Ericka.

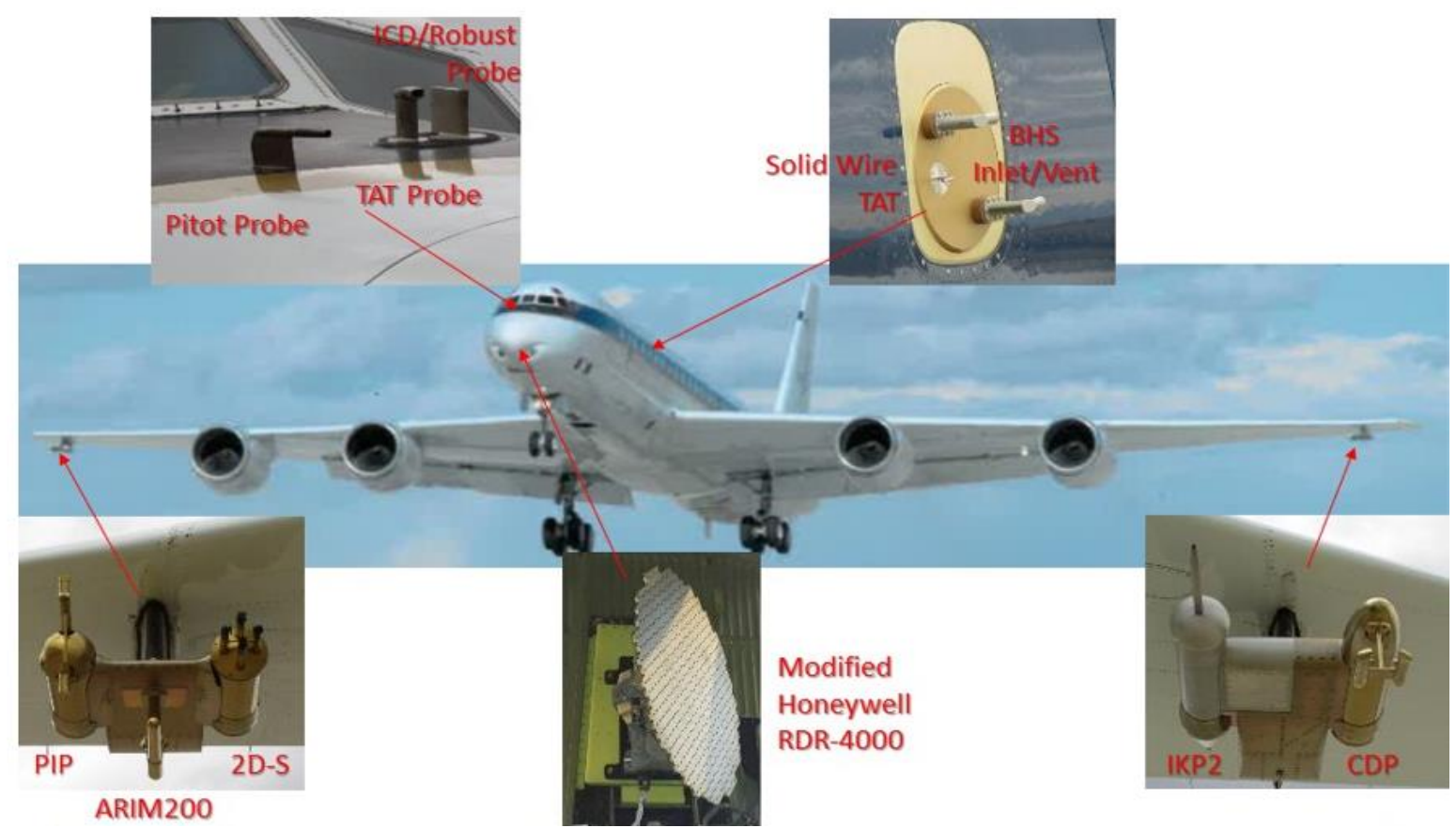

Figure 2. NASA's DC-8 and flight campaign instrumentation, including wingpods for IKP-2 and cloud particle spectra probes, fuselage-mounted instruments for background humidity, water content, and temperature, and a modified Honeywell RDR-4000 as primary weather radar.

† Based on criteria for RRF described above. 


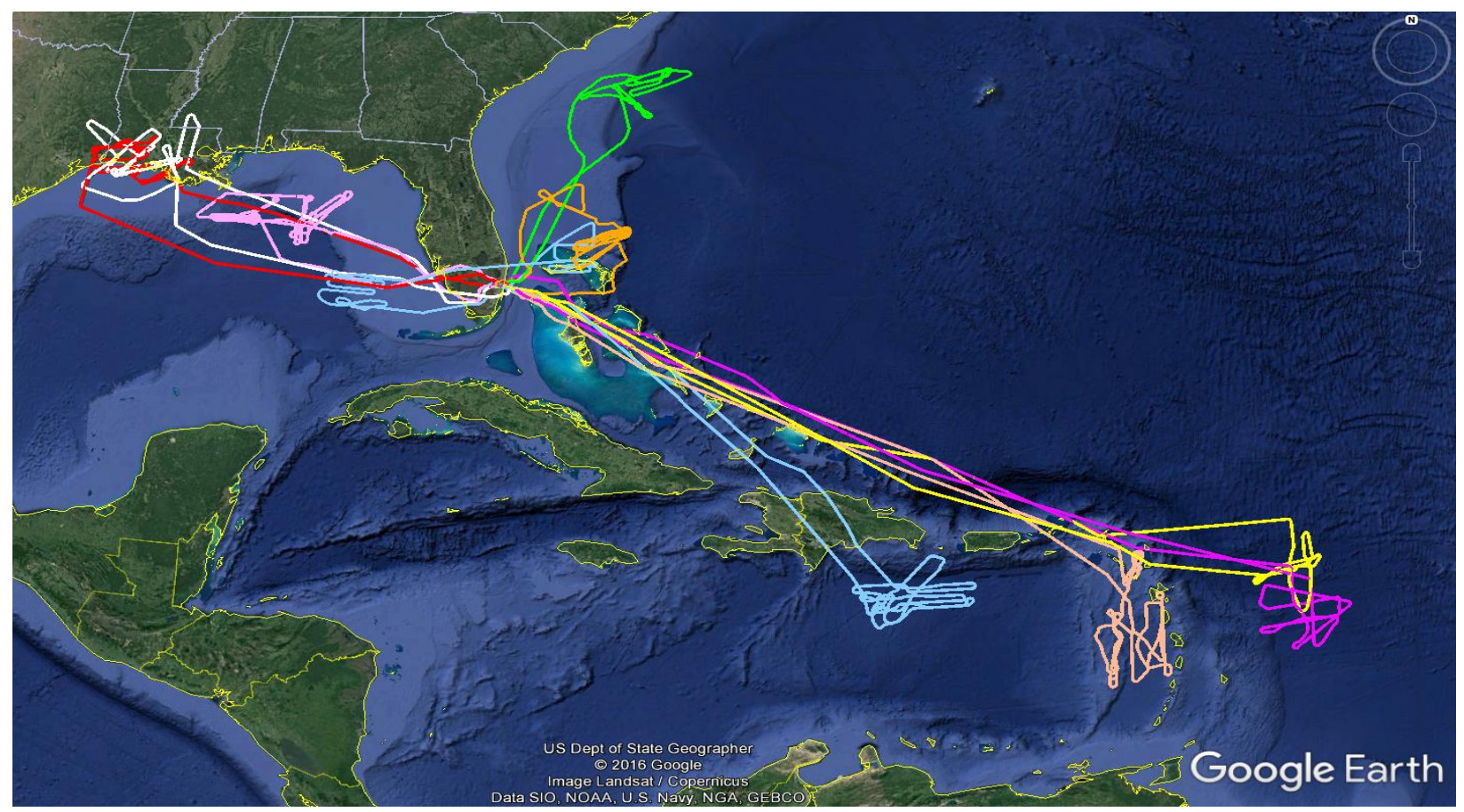

Figure 3. Depiction of the DC-8 Flight Tracks, 12-28 August 2015, for NASA HIWC Radar Campaign.

Table 1. Summary of flights for NASA's 2015 HIWC Radar Campaign

\begin{tabular}{|c|c|c|c|c|c|}
\hline Date & $\begin{array}{l}\text { Max } \\
\text { IWC } \\
g m^{-3}\end{array}$ & $\begin{array}{c}\text { Max Length } \\
\text { of Path } \\
\text { with IWC > } \\
1 \mathrm{~g} \mathrm{~m}^{-3}\end{array}$ & $\begin{array}{l}\text { Max } \\
\text { RRF } \\
\text { along } \\
\text { Track }^{\dagger \dagger}\end{array}$ & $\begin{array}{l}\text { Type of } \\
\text { System }\end{array}$ & General Location \\
\hline 12 Aug & 2.3 & $31 \mathrm{~km}$ & $27 \mathrm{dBZ}$ & Oceanic MCS & $\begin{array}{l}\text { Atlantic Ocean near } \\
\text { Southeastern US }\end{array}$ \\
\hline 13 Aug & 2.3 & $59 \mathrm{~km}$ & $32 \mathrm{dBZ}$ & Oceanic MCS & Atlantic Ocean near Florida \\
\hline 14 Aug & 2.7 & $64 \mathrm{~km}$ & $36 \mathrm{dBZ}$ & Oceanic MCS & $\begin{array}{l}\text { Atlantic Ocean and Gulf of } \\
\text { Mexico near Florida }\end{array}$ \\
\hline 16 Aug & 2.8 & $186 \mathrm{~km}$ & $30 \mathrm{dBZ}$ & Oceanic MCS & Gulf of Mexico \\
\hline 19 Aug & 2.3 & $114 \mathrm{~km}$ & $28 \mathrm{dBZ}$ & Coastal MCS & Louisiana Coast \\
\hline 21 Aug & 2.7 & $86 \mathrm{~km}$ & $29 \mathrm{dBZ}$ & Coastal MCS & Louisiana Coast \\
\hline 23 Aug & 2.3 & $139 \mathrm{~km}$ & $27 \mathrm{dBZ}$ & $\begin{array}{l}\text { Tropical Storm } \\
\text { Danny }\end{array}$ & $\begin{array}{l}\text { Atlantic Ocean east of } \\
\text { Lesser Antilles }\end{array}$ \\
\hline 26 Aug & 2.8 & $179 \mathrm{~km}$ & $30 \mathrm{dBZ}$ & $\begin{array}{l}\text { Tropical Storm } \\
\text { Erika }\end{array}$ & $\begin{array}{l}\text { Atlantic Ocean east of } \\
\text { Lesser Antilles }\end{array}$ \\
\hline 27 Aug & 3.2 & $125 \mathrm{~km}$ & $31 \mathrm{dBZ}$ & $\begin{array}{l}\text { Tropical Storm } \\
\text { Erika }\end{array}$ & $\begin{array}{l}\text { Caribbean Sea SE of } \\
\text { Puerto Rico }\end{array}$ \\
\hline 28 Aug & 2.9 & $220 \mathrm{~km}$ & $32 \mathrm{dBZ}$ & $\begin{array}{l}\text { Tropical Storm } \\
\text { Erika }\end{array}$ & $\begin{array}{l}\text { Caribbean Sea SW of } \\
\text { Puerto Rico }\end{array}$ \\
\hline
\end{tabular}


As mentioned above, no power-loss due to engine icing was noted during any of the flights; however, one TAT anomaly and several Pitot tube anomalies did occur during prolonged encounters with high concentrations of ice crystals.

In section three, we will summarize the observed characteristics of one of the flight days from the 2015 flight campaign, then in section five this event from this day will be examined via a numerical cloud model. The numerical cloud model, the Terminal Area Simulation System (TASS), is summarized in section four. In section six, the same numerical model and formulations also are applied to a benchmark case of a continental supercell hailstorm. Findings from both simulations are summarized in section seven. The Appendix discusses an improved algorithm for determining the size particle intercept for snow. The relationship is derived from the August 2015 flight data, and it is applied in the numerical simulations for the coastal MCS, as well as the continental supercell hailstorm.

\section{19 August 2015 Flight}

Around 0730 UTC on 19 August, a region of convection began to grow offshore of Galveston Bay, Texas. This convection expanded to become a long-lasting coastal MCS that moved slowly east-northeastward along the Louisiana coast (Figs. 4 and 5). The MCS appeared to be sustained by bands of convection flowing into the system from the Gulf, and a large cloud canopy that capped the system covered much of Louisiana. Developing cumulus towers appeared to supply the southern end of these convective bands (Fig. 6). Further upstream and underneath the cloud canopy, a region of steady rain fell over a wide area near the center and northern portion of the MCS.

The most intense convection and the highest/coldest cloud tops were associated with the inflowing convective bands, located near the coast of Louisiana, extending underneath the southern edge of the MCS cloud shield. These convective cells contained high radar reflectivity, especially at low levels. They also were very active with lightning. Movement of the convective cells were from the south-southwest toward the center of the MCS, and new cells formed at the southern edge to maintain the bands. The lateral separation between the inflowing bans was roughly about 45 $\mathrm{km}$. This banded convection is evident from visible satellite, but less so from infrared imagery due to partial obscuration from the overhanging cloud canopy. The MCS began to weaken after 1800 UTC as it moved through southeastern Louisiana and into Mississippi.

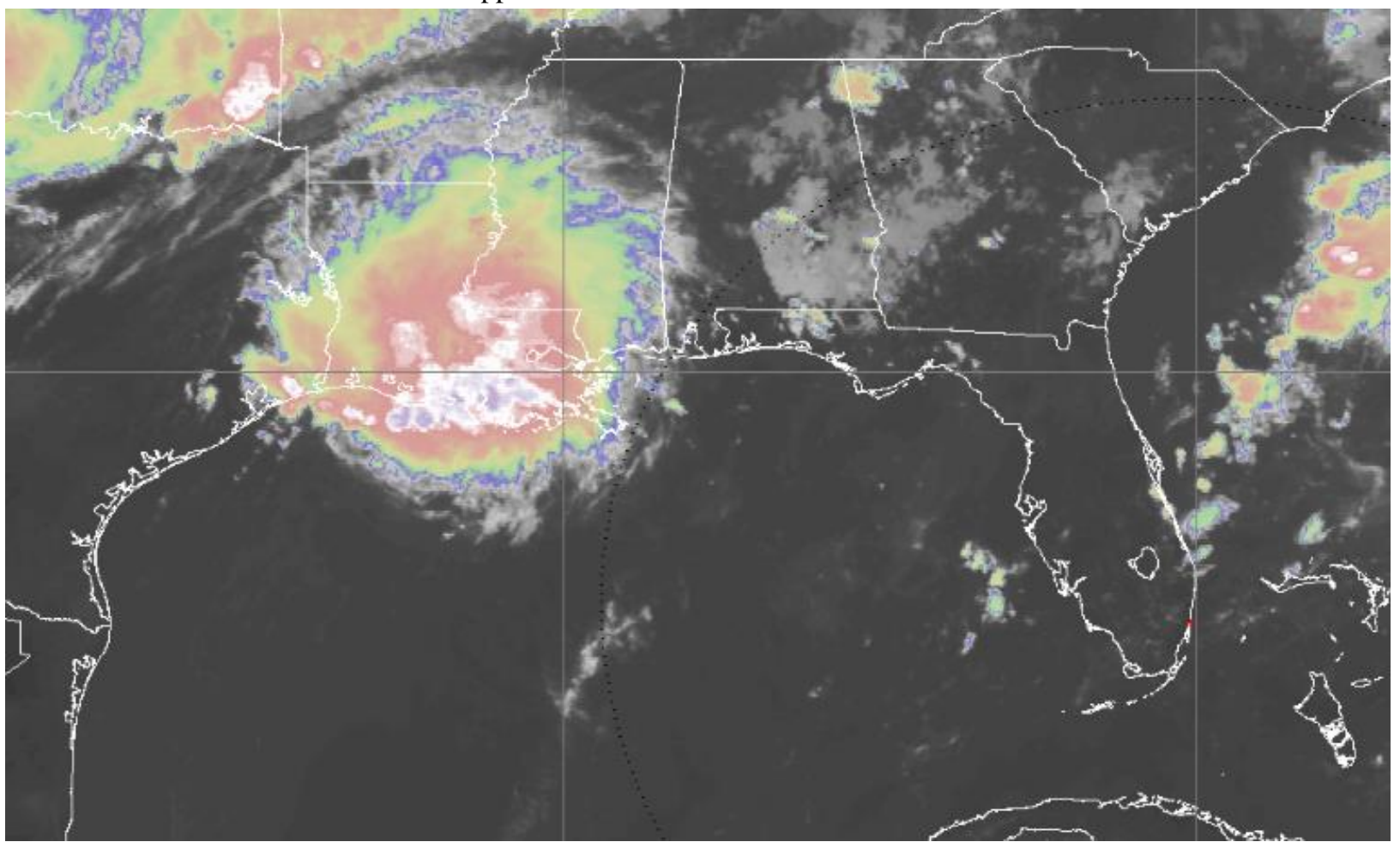

Figure 4. GOES Infrared Imagery for 1600 UTC, 19 August 2015. Coldest cloud tops (purple, 205K) are along the Louisiana Coast (Courtesy NASA Langley Satellite Group).

Eleven passes by the DC- 8 were made through the MCS over a 41/2-hour period (Fig. 7), at elevations ranging from 29,000 -37,000 ft standard mean sea level (MSL). Ice crystals were encountered on these passes, with sustained levels 
at high concentrations measured on at least two of the passes. The peak ice water content measured by IKP-2 was 2.3 $\mathrm{g} \mathrm{m}^{-3}$ with the longest duration having $1 \mathrm{~g} \mathrm{~m}^{-3}$ or greater persisting over a $114 \mathrm{~km}$ path or during about $10 \mathrm{~min}$ of flight.
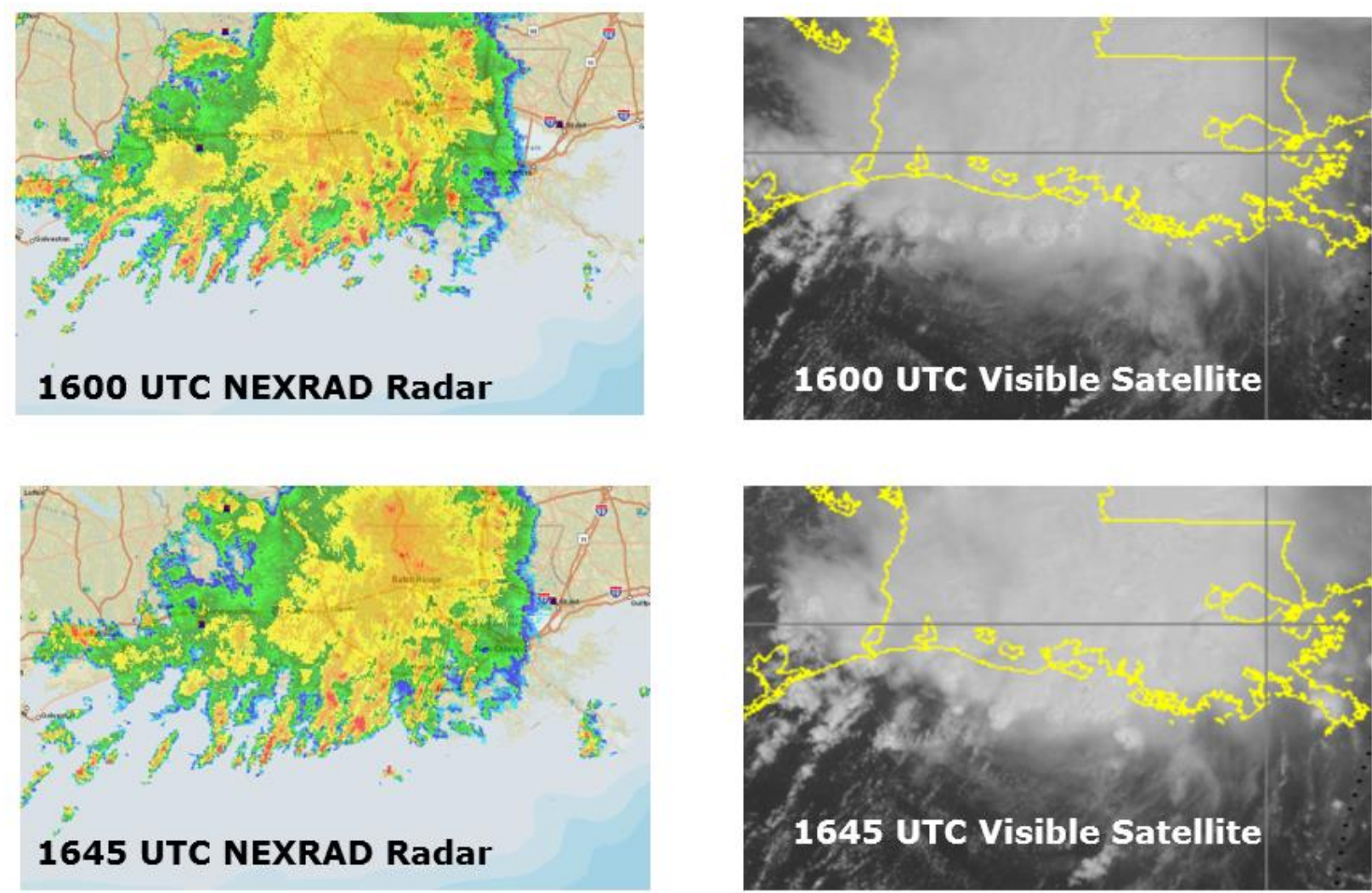

Figure 5. Low-level radar reflectivity from NEXRAD Radar (left column) compared with visible satellite imagery (right column) at 1600 UTC (top row) and 1645 UTC (bottom row). All four plots are of the same spatial scale. Banded convective lines are feeding into the MCS from the Gulf of Mexico.
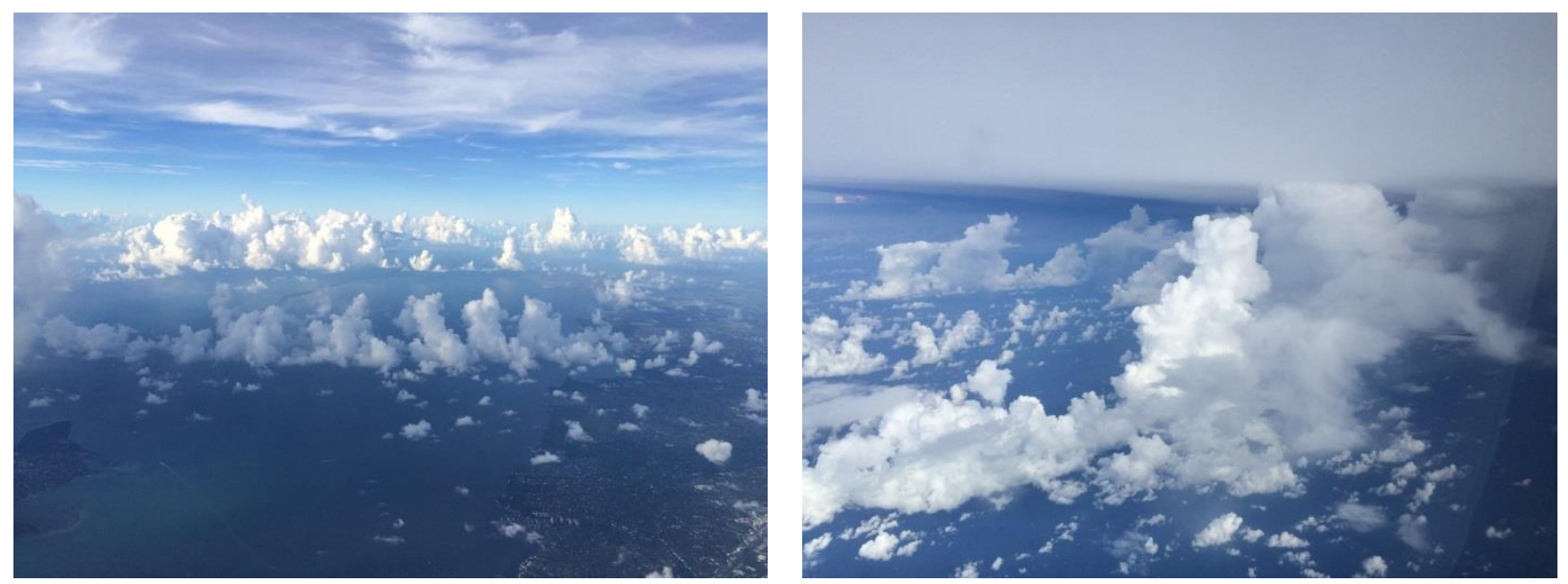

Figure 6. Lines of towering cumulus feeding into southern end of the Louisiana MCS and growing upward through the overhanging cloud canopy. Photographs from window of DC-8 courtesy of Stephanie DiVito (FAA). 


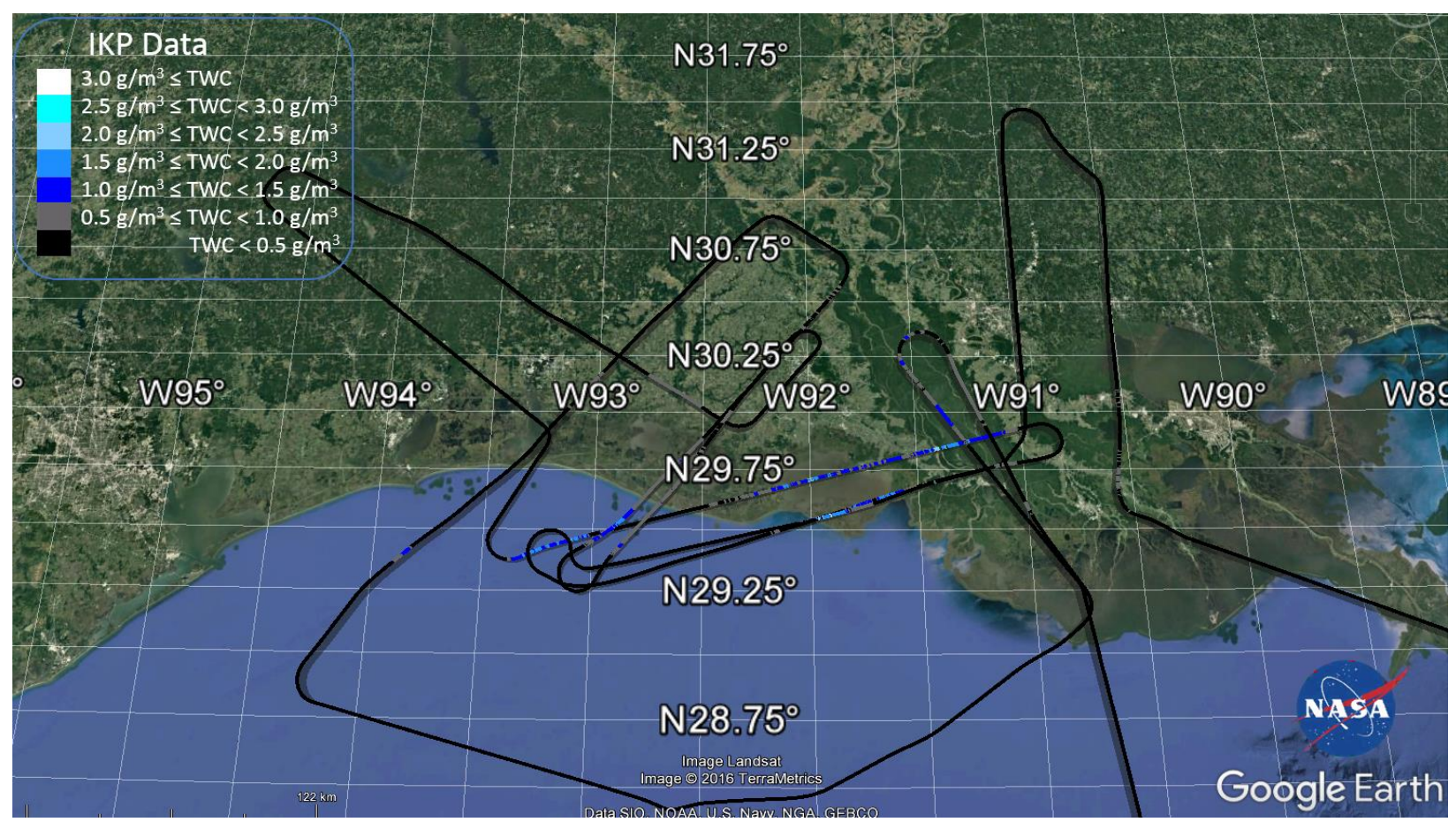

Figure 7. Flight path of DC-8 and measured ice water concentration from Ice Kinetic Probe for 19 August 2015.

Highest ice water concentrations seem to be located in the southern portion of the MCS, where the convective lines were feeding into the system. The DC-8 encountered persistent regions of significant ice water concentration in the two flight-legs along the Louisiana Coast, but less so in other regions (Fig. 7). Only weak concentrations were measured in the northern regions and near the center of the cloud system where steady rain occurred.

Although no engine irregularities were detected, other events did happen. Anomalies in airspeed due to icing of both Pitot tube systems occurred during penetration of HIWC conditions. Also during these ice crystal encounters, the DC-8 experienced: 1) view of snow specks or ice particles hitting windows and being sucked into the engines, 2) IFR conditions, 3) rime ice developing on both the Pitot tube and TAT probe outside the cockpit window, 4) light turbulence, and 5) benign values of RRF appearing on the ship radar.

This flight-day is of interest because of the storm systems structure, which is unlike the MCS from the Darwin, Australia, campaign that we have recently simulated. ${ }^{10}$ In addition, National Weather Service NEXRAD radar (ground-based WSR-88D) ${ }^{16}$ data is available to supplement our analysis. During many of the flights that were on other days, the DC- 8 was not in range of ground-based radars.

A scatter plot of the short-range ( $1 \mu \mathrm{s}$ pulse) airborne radar reflectivity factor $v s$ measured ice water content for 19 August is shown in Fig. 8. Values for IWC are measured by the IKP-2 and averaged over five seconds. The criteria for determining the RRF is that it must be detected within 1- $\mathrm{km}$ of the DC-8. Additionally, it must be detected within an altitude range of $\pm 150 \mathrm{~m}(500 \mathrm{ft}$ ) of the flight path, and laterally within the antenna azimuth angle of a beam width ( \pm 2 degrees). These criteria were put into place to best represent the RRF of the air that is actually encountered by the aircraft. Note that median values for RRF asymptote to near $20 \mathrm{dBZ}$ when IWC increases to greater than $1 \mathrm{~g} \mathrm{~m}^{-3}$. Additionally, there is a large range of scatter exists between RRF and IWC. Although not shown, plots from each of the other days appear very similar, having low values of RRF and a weak relationship to ice water content. This would suggest that RRF alone may be an unsuitable measurement parameter for detecting HIWC.

An example from the display of the airborne research radar is shown in Fig. 9, as the aircraft heads northeastward across the Louisiana Coast. This plot is sampled at a time when high ice water concentrations were being encountered and the aircraft was passing over convective bands within the southern region of the MCS. With level tilt, the radar displays mostly green (less than $30 \mathrm{dBZ}$ ) over a wide area. Areas of higher reflectivity are evident with the downward tilted scan and are associated with the convective bands crossing obliquely to the flight path. Distinguishable radar signatures for HIWC encounters do not seem to stand out.

American Institute of Aeronautics and Astronautics 


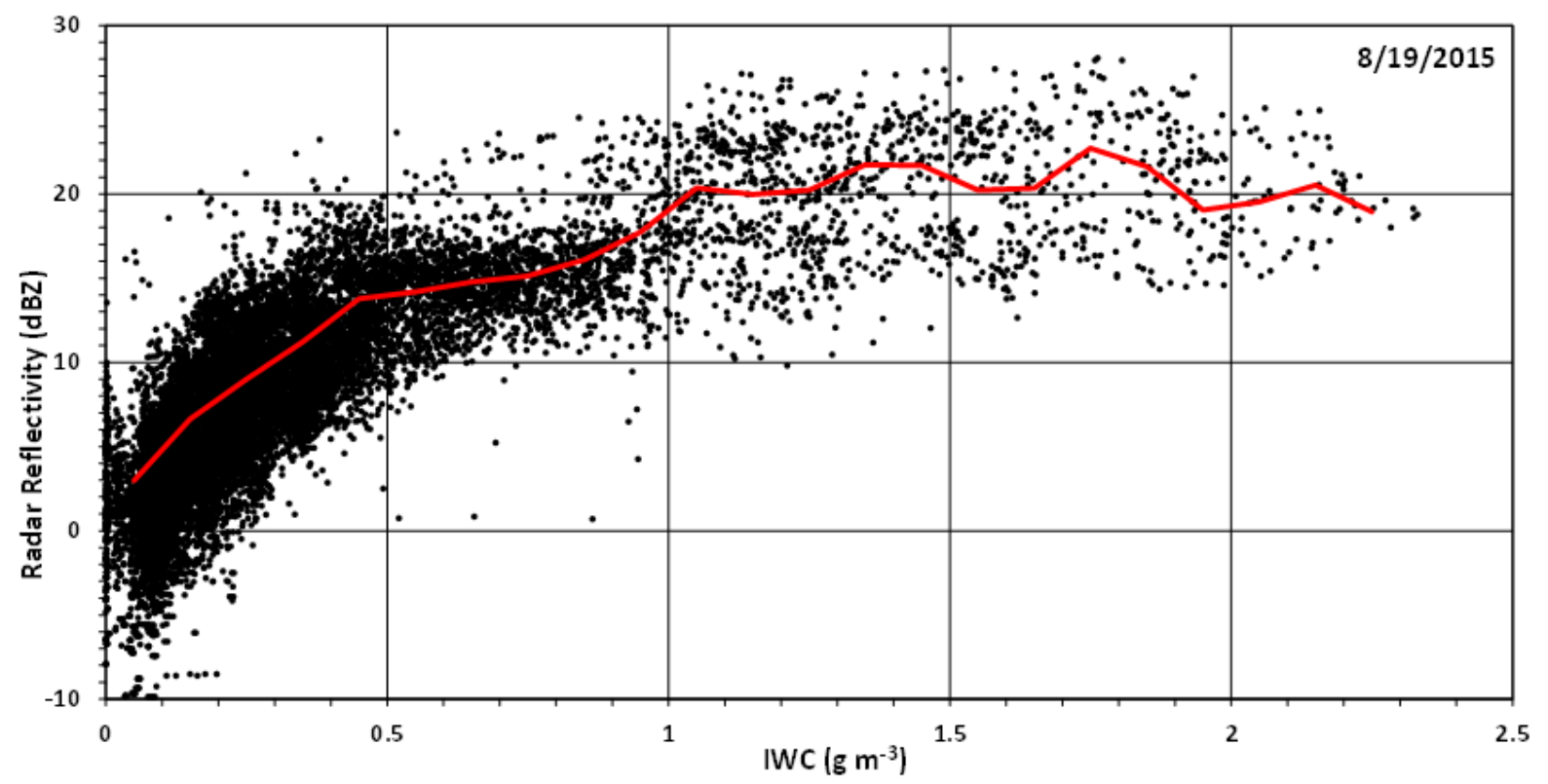

Figure 8. Peak short-range radar reflectivity factor (within 1-km of aircraft) vs ice water content measured by IKP-2 for 19 August. The median ice water concentration is represented by the red curve.
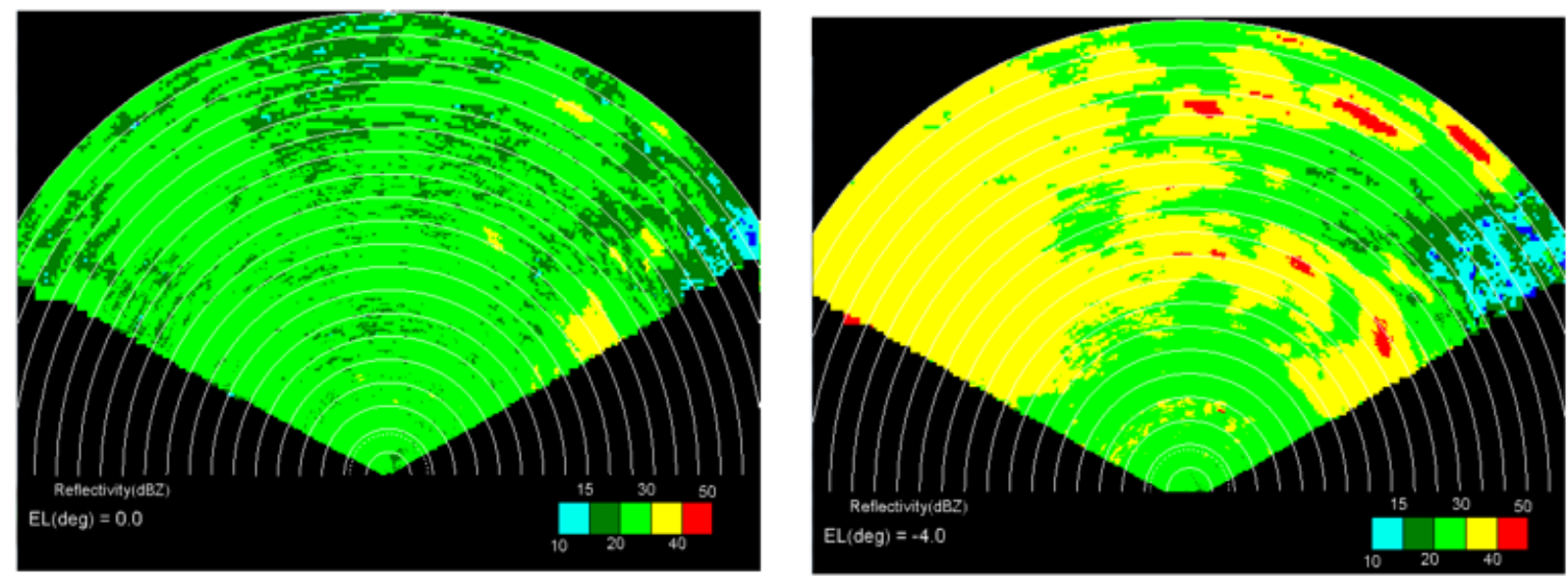

Figure 9. One-hundred kilometer scan of radar reflectivity factor from the NASA Airborne Radar at 1634 UTC during HIWC encounter on 19 August, for level tilt (left) and $-4^{\circ}$ tilt (right). Range rings every $5 \mathrm{~km}$. The aircraft is at $8.85 \mathrm{~km}(29 \mathrm{kf})$ MSL on an ENE baring just north of the Louisiana Coast.

\section{Numerical Model}

A three-dimensional, time-dependent numerical cloud model is used to investigate and shed further light on the characteristic of this HIWC producing storm system. Numerical simulations are performed with NASA's Terminal Area Simulation System (TASS), ${ }^{17,18,19}$ which has a history of being used to study microburst windshear, ${ }^{20,21,22,23}$ convection induced turbulence, ${ }^{24,25}$ aircraft wake vortices, ${ }^{26,27,28,29}$ atmospheric boundary layer turbulence, ${ }^{30,31,32}$ tornadoes, ${ }^{33}$ and severe convection. ${ }^{34}$ Recently, it has been applied to the study of HIWC, such as a MCS convective line observed during a HAIC-HIWC flight campaign at Darwin Australia. ${ }^{10}$ The numerical model has prognostic equations for velocity, potential temperature, pressure, and water substances (water vapor, cloud droplet water, rain water, cloud ice crystal water, snow, and hail/graupel). TASS also has over 60 cloud microphysical submodels, for cloud and precipitation development. The TASS formulation includes all three-phases of latent heat exchanges for water, and has a subgrid-turbulence closure formulation based on Vreman. ${ }^{35}$ Boundary conditions can be periodic,

American Institute of Aeronautics and Astronautics 
open, or closed, and in combination. The surface boundary is assumed flat, and can represent either ocean or a flat ground. The impermeable surface boundary is nonslip with a parameterization for surface stress based on MoninObukhov similarity theory. ${ }^{36}$ Initiation packages are available for triggering cumulus convective systems, turbulence, microbursts, and aircraft wake vortices. A summary of the salient characteristics of TASS are in Table 2 . The TASS model has over a 30-year history of supporting NASA programs. ${ }^{37}$

\section{Table 2. Salient Features in TASS}

- Ambient conditions initialized with atmospheric sounding

- Arakawa C-grid staggered numerical mesh

- Bulk parametrizations for cloud microphysics (over 60 sub-models)

- Compressible, time-split formulation

- Efficient and accurate conservative numerical schemes with little or no numerical diffusion

- Ground-stress based on Monin Obukhov Similarity Theory

- History of application to aviation weather and safety problems

- Initialization packages for: convective storms, microbursts, turbulence, planetary boundary layer, and aircraft wake vortices

- Large Eddy Simulation with subgrid scale turbulence closure

- Liquid, vapor, and ice phase microphysics

- Massively parallel interface, scales efficiently with multiple processors as used on highperformance supercomputer clusters

- Meteorological framework

- Model simulations validated with field data and theoretical solutions

- Monotone upstream-centered schemes for water substance

- NonBousssinesq equation set

- Nonreflective boundary conditions for open boundaries

- Option of either open or periodic lateral boundaries

- Option for either periodic or impermeable top and bottom boundaries

- Prognostic equations for velocity, pressure, potential temperature, dust/insects, and water substance

- Storm-tracking, movable grid domain

- Variable time step to ensure CFL criteria for numerical stability

- Vreman subgrid turbulence closure model with modification for stratification and flow rotation

- Water substance represented by water vapor, liquid cloud water, rain, cloud ice, snow, and hail/graupel

- Wet and dry growth for hail and snow

\section{A. Numerical Approximations}

The TASS model equations are discretized using quadratic-conservative fourth-order finite-differences in space for the calculation of momentum and pressure fields, ${ }^{38}$ and the third-order upstream-biased Leonard scheme ${ }^{39}$ is used to calculate the transport of potential temperature and water vapor. A Monotone Upstream-centered Scheme for Conservation Laws (MUSCL)-type scheme after van Leer $^{40,41}$ is used for the transport of water substance variables. Such a scheme is mostly free of negative water production from numerical error. The Klemp-Wilhelmson timesplitting scheme ${ }^{42}$ is used for computational efficiency, in which the higher-frequency terms are integrated by enforcing the CFL criteria to take into account sound wave propagation due to compressibility effects. The remaining terms are integrated using a larger time step that would be appropriate for anelastic and incompressible flows. The Adams-Bashforth scheme is assumed for time differencing of momentum and pressure for both large and small time 
step approximations. The TASS model is programmed in FORTRAN and operates efficiently on massively-parallel computer architectures using Message Passing Interface (MPI) library calls.

The numerics in TASS are very accurate, highly efficient, and nondissipative. The integrity and accuracy of the numerical and core dynamics is evaluated by performing a number of validation tests. These include validation of numerical simulations with special cases for analytical and existing high-order numerical solutions, such as Beltrami flow, ${ }^{43,44}$ compressible Taylor-Green Vortex ${ }^{45,46,47}$ solutions, and other test cases. ${ }^{48}$ TASS has been found to achieve high accuracy and efficient timing in these comparison tests. Furthermore, to ensure continued accuracy and fidelity, simulations from TASS are performed and evaluated against several baseline cases following any modification to either the software or operating system. These tests are designed to test most components and maintain efficiency, robustness, and accuracy of the model.

\section{B. Cloud Microphysics}

TASS has over 60 bulk cloud microphysical submodels similar to those used by Lin et al., ${ }^{49}$ and Rutledge and Hobbs. ${ }^{50}$ The autoconversion of cloud droplets into rain is based on drop growth studies by Berry and Reinhardt, ${ }^{51,52}$ and allows for differences in cloud droplet sizes usually found between continental and maritime locations. ${ }^{17}$ Rain is assumed to have an inverse-exponential drop distribution with an intercept that increases with rainwater concentration, ${ }^{53}$ in accordance with data measured by Sekhon and Srivastava. ${ }^{54}$

The prediction of ice particles are divided into three different categories: 1) ice crystal water - which represents small hexagonal ice crystals, 2) Snow - which represents larger precipitating ice particles, and 3) hail (or graupel) - which represents even larger more dense particles that are produced from freezing rain drops and riming snow particles. The ice crystal water is assumed to have a monodispersed particle size that is limited to diameters no greater than about $200 \mu \mathrm{m}$. These particles are represented by hexagonal plates, have little fall velocity, and grow primarily by diffusion of vapor. The snow category assumes spherical particles that have an inverse exponential size distribution. The size distribution intercept for snow, Nos, increases with decreasing temperature and snow water content. The relationship for Nos is developed from particle size distribution (PSD) data collected during the 2015 Florida flight campaign, and is described with more detail in the Appendix. A category for hail and graupel particles also assume an inverse exponential size distribution, but with a smaller intercept and a larger particle density than for snow. Wet and dry growth for hail follows the formulation in Musil. ${ }^{55}$ Several of the key parameters assumed for the particle distributions are summarized in Table 3.

Radar reflectivity factor is diagnosed in TASS based on the predicted water content and the assumed particle distributions. These relationships for RRF use the same particle distributions that are assumed in the microphysical submodels. The approach assumes Rayleigh scattering and is based on Smith et al. ${ }^{56}$ For example, the radar reflectivity factor for rain is:

$$
Z_{R}=\int_{0}^{\infty} N\left(D_{R}\right) D_{R}^{6} d D_{R}
$$

The particle size distribution can be effectively represented by an inverse exponential distribution as

$$
N\left(D_{R}\right)=N_{0 R} e^{-\lambda D_{R}}
$$

where $N_{O R}$ is the intercept of the drop size distribution and $\lambda$ is the slope. The contribution of radar reflectivity factor from rainwater can be determined with the relationship for $N o_{R}$ as assumed in deriving the microphysics used in TASS (Table 3):

$$
\mathrm{Z}_{\mathrm{R}}\left[\mathrm{mm}^{6} / \mathrm{m}^{3}\right]=9.4 \times 10^{3} M_{r}^{1.468}
$$

where spherical drops are assumed, and $\mathrm{M}_{\mathrm{r}}$ is the rainwater content in $g \mathrm{~m}^{-3}$.

The radar reflectivity factor for ice particles consider the dielectric factors for ice and water and depend upon whether the particle is undergoing either wet or dry growth. For example, the contribution to radar reflectivity factor for "dry" snow adjust for the melted diameters is:

$$
Z_{S}=\frac{\left|K_{I}\right|^{2}}{\left|K_{W}\right|^{2}} \frac{\delta_{S}^{2}}{\delta_{w}^{2}} \int_{0}^{\infty} N\left(D_{S}\right) D_{S}^{6} d D_{S}
$$

American Institute of Aeronautics and Astronautics 
The values assumed for the dielectric factors are for wavelengths employed in weather Radars. ${ }^{57}$ The contribution to RRF from hail/graupel, ice crystals, and cloud droplets are computed similarly. For "wet" hail, the contribution is adjusted for Mie scattering as in Smith et al. ${ }^{56}$

Table 3. Key relationships and assumptions in TASS Microphysics

\begin{tabular}{|c|c|c|c|}
\hline Category & $\begin{array}{c}\text { Size Distribution and } \\
\text { Intercept }\left(\mathrm{m}^{-4}\right)\end{array}$ & $\begin{array}{l}\text { Particle Density } \\
(\delta)\end{array}$ & Comment \\
\hline $\begin{array}{l}\text { Liquid Cloud } \\
\text { Water }\end{array}$ & Monodispersed & $1000 \mathrm{~kg} \mathrm{~m}^{-3}$ & $\begin{array}{c}N_{C D} \text {, number of droplets per } \\
\text { volume is an input }\end{array}$ \\
\hline Rain & $\begin{array}{c}\text { Inverse exponential } \\
N_{O R}=2.25 \times 10^{7} M_{R}^{0.375}\end{array}$ & $1000 \mathrm{~kg} \mathrm{~m}^{-3}$ & $\begin{array}{l}\text { Intercept increases with } \\
\text { rainwater content, } \\
M_{R}\left(g^{-3}\right)\end{array}$ \\
\hline $\begin{array}{l}\text { Cloud lce } \\
\text { Crystal Water }\end{array}$ & Monodispersed & $\begin{array}{c}\text { Particle mass }(\mathrm{kg})= \\
0.1758 D_{i c}^{2.2}\end{array}$ & $\begin{array}{c}\text { Hexagonal plates } \\
\text { Diameter mostly }<200 \mu m\end{array}$ \\
\hline Snow & $\begin{array}{c}\text { Inverse exponential } \\
N_{O S}=10^{(7.44-0.0217 T c+X)} \\
\text { where } \\
X=M_{s}\left[1.053-M_{s}(0.15-\right. \\
\left.\left.0.004 M_{s}\right)\right] \\
\text { for } 4^{\circ} C>T C>-55^{\circ} \mathrm{C}\end{array}$ & $\begin{array}{c}100 \mathrm{~kg} \mathrm{~m}^{-3} \text { if } \\
\mathrm{Tc}<-12^{\circ} \mathrm{C}, \\
\text { Ramping to } 150 \mathrm{~kg} \mathrm{~m}^{-3} \\
\text { at } \\
\mathrm{Tc}>0{ }^{\circ} \mathrm{C}\end{array}$ & $\begin{array}{l}\text { Intercept increases with } \\
\text { decreasing temperature } \\
\text { and increasing snow } \\
\text { concentration, } M_{s}\left(g \mathrm{~m}^{-3}\right)\end{array}$ \\
\hline Hail/Graupel & $\begin{array}{l}\text { Inverse exponential, } \\
\text { Intercept is an input } \\
\text { parameter }\end{array}$ & $\begin{array}{l}\text { Either } 450 \mathrm{~kg} \mathrm{~m}^{-3} \\
\text { if graupel, or } \\
900 \mathrm{~kg} \mathrm{~m}^{-3} \text { if hail }\end{array}$ & $\begin{array}{l}\text { Intercept decreases with } \\
\text { temperature, when } \mathrm{Tc}>0^{\circ} \mathrm{C}\end{array}$ \\
\hline
\end{tabular}

\section{Numerical Simulation of 19 August Case}

In this section, the numerical simulation from the 19 August case is presented to help better understand the characteristics of this system. Comparisons with measured data are presented to substantiate the credibility of the numerical simulation.

\section{A. Configuration}

In modeling the HIWC conditions associated with this convective system, an approach similar to that used in the Darwin HIWC simulation ${ }^{10}$ is used. The domain of the model simulation is defined to represent a section of the MCS, rather than the full volume surrounding the weather system. Specifically, the model's computational domain is specified about one of the inflowing lines of convection (Fig. 10). Periodic lateral boundary conditions are assumed on the domain boundaries parallel to the convective line, and open lateral boundary conditions assumed on the ends. This configuration allows the simulated line to interact as if identical parallel lines exist on either side. This includes the interaction of the canopy outflow with the adjacent convective lines via the periodic boundaries. The domain also is rotated $21^{\circ}$ to align the model $y$-axis with the direction of the low-level shear vector. This results in the model domain being oriented along the convective line, since observed convection often orients itself in a line along the lowlevel shear vector.

The domain size and resolution (Table 4) is chosen to simulate the physics adequately and to resolve the essential three-dimensional scales of motion. The domain width of $45 \mathrm{~km}$ is based on the typical distance separating the inflowing convective lines. The grid size is chosen to concentrate the model grid points into a $45 \mathrm{~km} \times 150 \mathrm{~km}$ area. 


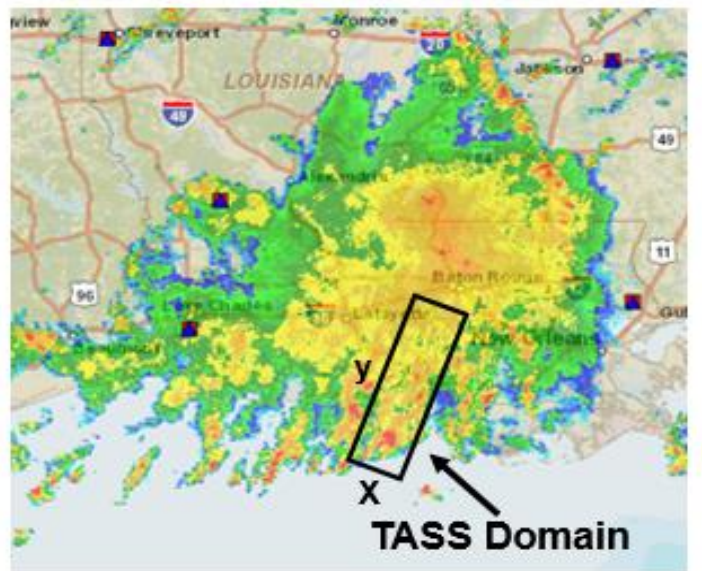

Figure 10. Model Domain size relative to MCS.

The assumed grid size is the same in all three directions $(150 \mathrm{~m})$ and is small enough to allow the resolution of important thermally-driven scales of motion.

The atmospheric sounding used as input is extrapolated from an operational weather forecast model, at a location just upstream from the system. This sounding (Fig. 11) possess strong convective instability and deep levels of moisture. This sounding also indicates a tropopause at $14 \mathrm{~km}$ MSL with a temperature of about $-62^{\circ} \mathrm{C}$ or $211 \mathrm{~K}$. Convective indices ${ }^{58}$ computed from the sounding indicate strong convective instability with a lifted index of about $-6^{\circ} \mathrm{C}$ and CAPE $=3400 \mathrm{~J} \mathrm{~kg}^{-1}$. The melting level is at $4900 \mathrm{~m}$ MSL.

The initial state of the numerical simulation is horizontally homogeneous and varies vertically according to the input sounding shown in Fig. 11. Convection is initiated by an artificial thermal impulse. A cool pool of air that resides near the surface over much of Louisiana and underneath the MCS, is ignored for the initial and boundary conditions. The boundary conditions for the ground are representative of a smooth ocean surface with constant temperature. Other input parameters for the simulation are representative of a tropical oceanic environment (Table 5). The simulation is integrated over a 4-hour period, with convection occurring through the full period. In our simulations, time (t) is in reference to time of initiation, and values for the $x$ and $y$ coordinates are in reference to the initial triggering impulse.

\section{B. Results}

The numerical simulation generates a long-lasting system with a convective line oriented in the direction of the low-level shear vector of the environmental winds. The cyclic (i.e. periodic) boundary conditions on the left and right sides of the domain, account for the effect of multiple lines, including the interaction between the lines. The type of convection is multicellular, ${ }^{11}$ with overshooting tops penetrating through the tropopause by about $600 \mathrm{~m}$. The system produces persistent HIWC conditions at storm upper levels, within an expanding cirrus shield fed from the multi- 
cellular convection. A comparison of the low-level radar reflectivity factor from the model simulation with the observed NEXRAD reflectivity is shown in Fig. 12.

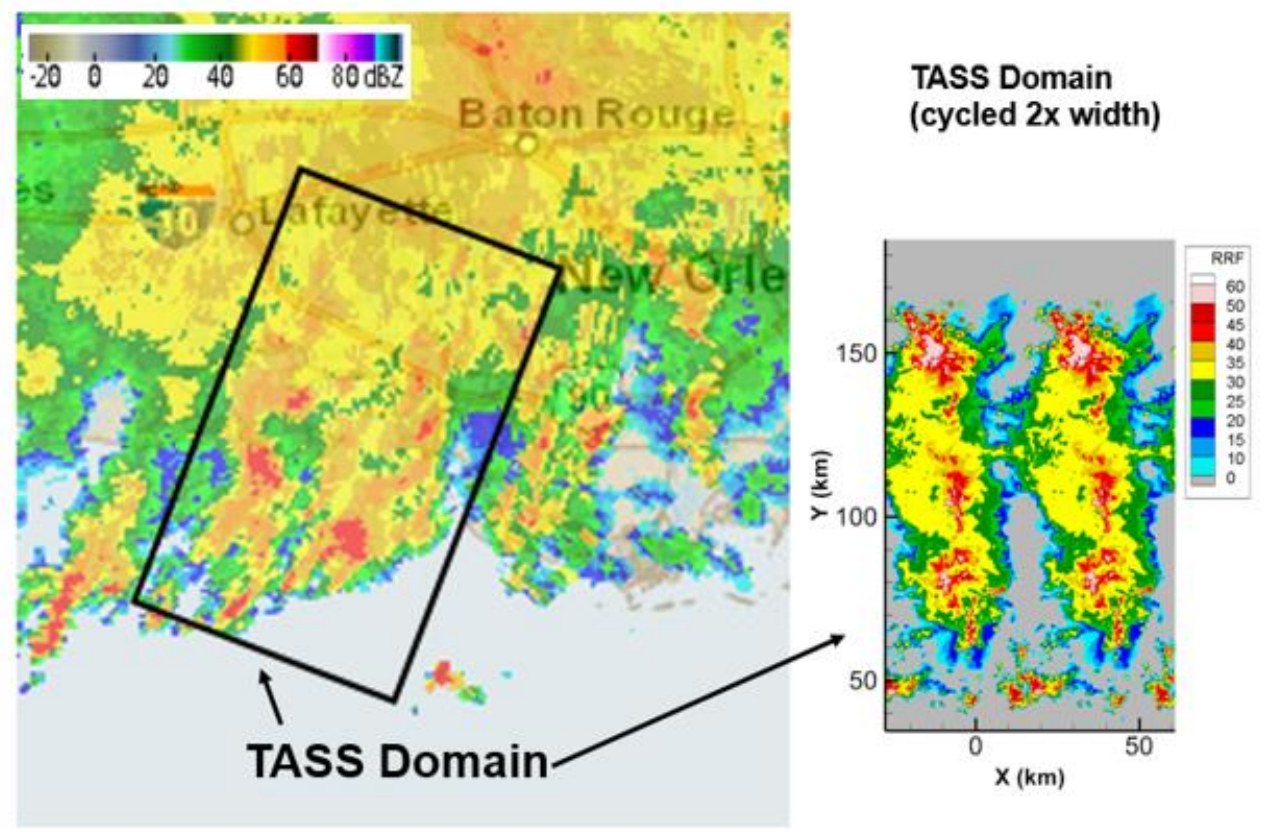

Figure 12. Comparison of low-level RRF between NEXRAD (left) and TASS (right). Observed NEXRAD for Louisiana coast at 1645 UTC. Simulated RRF at $4 \mathrm{~km}$ altitude and $3 \mathrm{hr}$ 45min. Outline of TASS domain shown $(90 \mathrm{~km} \times 150 \mathrm{~km})$.

Updrafts within the convective line generate precipitation and carry snow particles and ice crystals to the upperregions of the troposphere. At upper levels, the expanding outflow coalesces with the upper-level anvil outflow from adjacent lines to form a large overhanging canopy (Fig. 13). The general comparison between observations and numerical simulation are summarized in Table 6.

Horizontal cross-sections at two altitudes for RRF and IWC are shown in Figs. 14 and 15. The chosen altitudes represent the two flight altitudes for the DC-8 during each of two passes when persistent IWC was measured. The timing of the slices are at a model time of $3 \mathrm{hr}: 45 \min$ (from the start of initialization), and represent a time when the simulated system has reached a mature state. Profiles are extracted along the dashed line shown in the figures and are compared to that measured by the DC-8 (Fig. 16).

In Fig. 14, the numerically simulated ice water concentration (ice crystal, snow, and graupel water, combined) as well as the

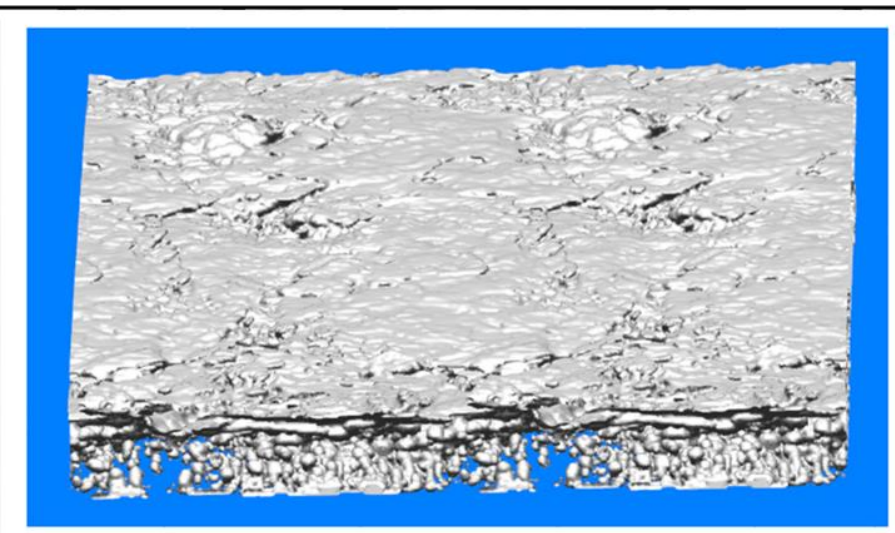

Figure 13. Simulated three-dimensional cloud surface viewed from above and from south-southwest.

RRF are shown at flight level $29 \mathrm{kft}(8850 \mathrm{~m})$. Peak ice water concentrations exceeding $3 \mathrm{~g} \mathrm{~m}^{-3} \mathrm{can}$ be found within

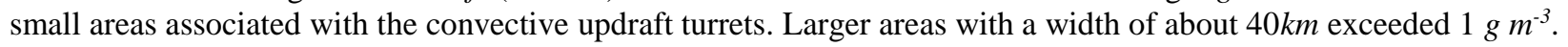
Radar reflectivity factor values are generally less than $30 \mathrm{dBZ}$ and would appear green on the weather radar display of most aircraft. Locally higher values of RRF were found within the strong updraft cores that carry graupel and other ice particles. The RRF in Fig. 14, does show large areas of low RRF, but not as uniform as from the flight radar (cf. Fig. 9). A more appropriate comparison would be between the RRF observed by the DC- 8 with a simulation of its Xband radar using the TASS fields as input. 
Table 6. Comparison of general features between observed and numerically simulated for 19 August 2015 case.

\begin{tabular}{|c|c|c|}
\hline Feature & Observed & Simulated with TASS \\
\hline Orientation of convective lines & $\begin{array}{l}\text { SSW-NNE with } 45 \mathrm{~km} \\
\text { separation between lines }\end{array}$ & $\begin{array}{l}\text { SSW-NNE with } 45 \mathrm{~km} \\
\text { separation between lines }\end{array}$ \\
\hline Cloud top elevation & $\sim 14-15 \mathrm{~km}$ & $14.6 \mathrm{~km}$ \\
\hline Coldest cloud top temperature & $\sim 200 \mathrm{~K}$ & $203 K$ \\
\hline Cell movement from & $210^{\circ}$ at $10 \mathrm{~m} / \mathrm{s}$ & $221^{\circ}$ at $11 \mathrm{~m} / \mathrm{s}$ \\
\hline Direction of anvil canopy expansion from & Southwest & Southwest \\
\hline Convective line movement from & $290^{\circ}$ at $6 \mathrm{~m} / \mathrm{s}$ & $291^{\circ}$ at $4.5 \mathrm{~m} / \mathrm{s}$ \\
\hline System lifetime & $>10$ hrs & $>4 h r s$ \\
\hline $\begin{array}{l}\text { Width of area with } R R F>20 \mathrm{dBZ} \text { at cruise } \\
\text { altitudes }\end{array}$ & $>50 \mathrm{~km}$ & $40 \mathrm{~km}$ \\
\hline
\end{tabular}

At a slightly higher altitude (Fig. 15), regions with HIWC cover smaller areas and have lower values of RRF. This is consistent with the measurements from the DC-8, which encountered shorter durations of IWC greater than 1 $\mathrm{g} \mathrm{m}^{-3}$, and detected lower values of RRF, after changing to a $5 \mathrm{kft}$ higher altitude on a subsequent pass through the active regions near the Louisiana coast.

Figure 16 shows a comparison of measured and model-extracted profiles for RRF and IWC. The DC-8 flight profiles relative to the MCS are shown in Fig. 17. The TASS profiles are extrapolated at the two different altitudes and headings flown by the DC-8, and are compared with values measured by the DC- 8 . At the lower elevation, both the TASS and DC-8 profiles indicate a nearly steady RRF of about 20-25 dBZ and IWC mostly between 1- $2.5 \mathrm{~g} \mathrm{~m}^{-3}$. At the higher elevations both TASS and DC-8, show consistent magnitudes of variation, with the RRF varying between 0 to $20 \mathrm{dBZ}$, and the IWC mostly remaining below $0.5 \mathrm{~g} \mathrm{~m}^{-3}$. Both profiles at the higher elevation do show a small region where IWC approached $2 \mathrm{~g} \mathrm{~m}^{-3}$. Although peak values and duration of encounters seemed similar in magnitude, the variability of RRF and IWC appears greater in the modeled profiles.

In Fig. 18, vertical cross-sections of the simulated RRF and IWC fields are taken along the assumed flight path in Fig. 14. Note that large regions of IWC greater than $1.5 \mathrm{~g} \mathrm{~m}^{-3}$ (orange) extend over a large region along and below the lower-altitude flight path. Peak values occur between altitude ranges of 7.5-9.5 km AGL, and drop off significantly above $10 \mathrm{~km}$ AGL. The corresponding RRF shows larger values below the melting level (around $5 \mathrm{~km}$ AGL), and very weak values above $10 \mathrm{~km} \mathrm{MSL}$. Also, note that regions with significant IWC can extend above regions with low or no detectable RRF near the ground.

In summary, a persistent coastal MCS system with HIWC is numerically simulated and its results compared with data from the 2015 Florida Radar flight campaign. The system is sustained by bands of convection inflowing from the Gulf of Mexico and is capped by a large canopy cloud consisting of mostly ice crystals. The simulation showed that the coalescence of the expanding anvils from the convective cells resulted in a cloud canopy that may obscure the banded structure and other low-level features from detection with satellite. The model simulated cloud top elevations and movement of cells appear similar to observations. Largest concentrations of ice water were found in the simulation between 7.5 and $9.5 \mathrm{~km}(25 \mathrm{kft}-31 \mathrm{kft}) \mathrm{MSL}$, where environmental temperatures were between $-19^{\circ} \mathrm{C}$ to $-33^{\circ} \mathrm{C}$. The range of elevations with the largest RRF were between the surface and $6 \mathrm{~km}(20 \mathrm{kft}) \mathrm{MSL}$. The TASS-extracted profiles compare reasonably with the measurements from DC-8, although some differences in variability were noted.

American Institute of Aeronautics and Astronautics 

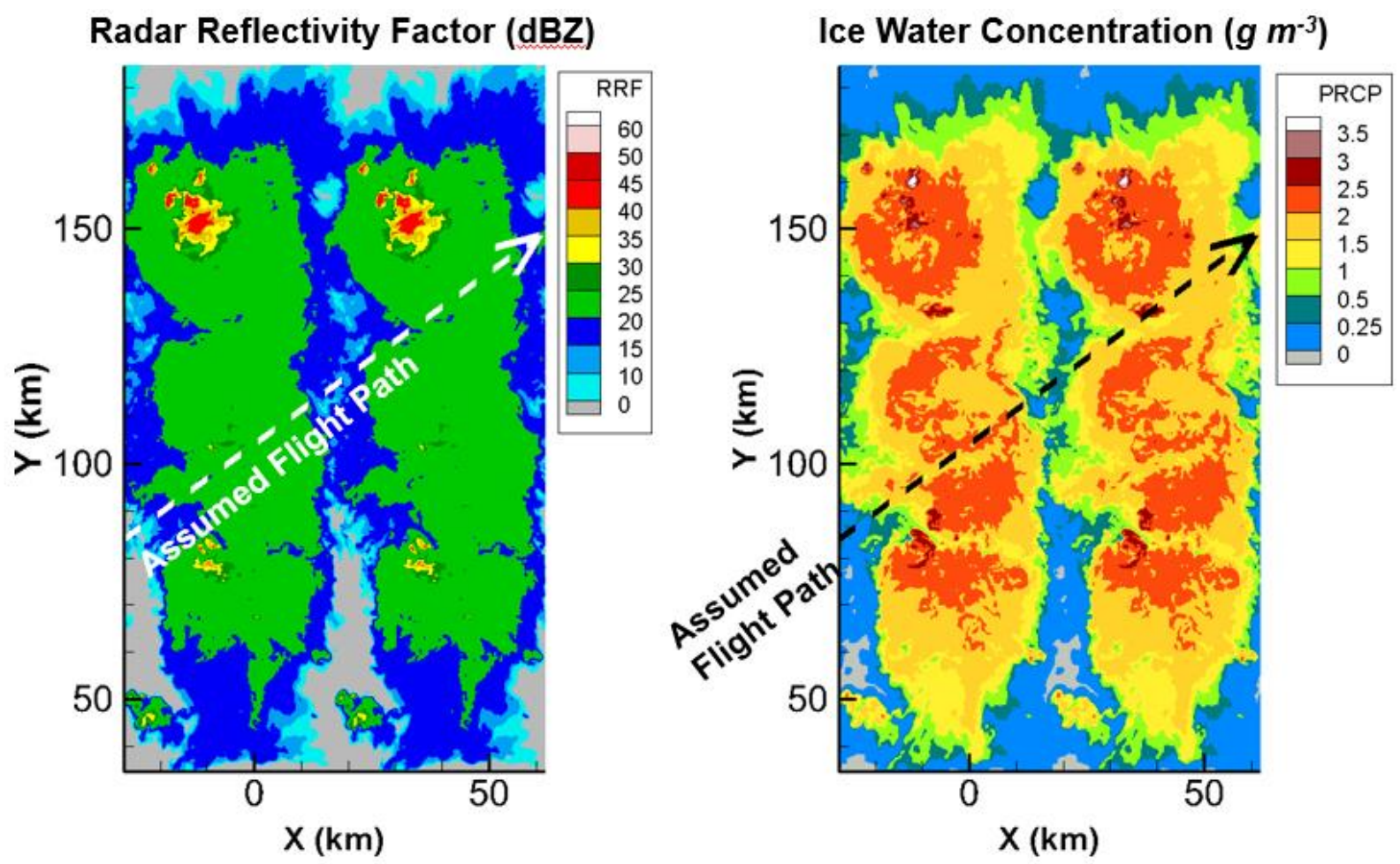

Figure 14. Simulated RRF (left) and IWC (right) from TASS simulation at an altitude of $8850 \mathrm{~m}$ (flight level $29 \mathrm{kft}$ ) and $3 \mathrm{hr}$ and $45 \mathrm{~min}$. The TASS IWC field is the sum of all ice water (ice crystal water + snow + graupel)
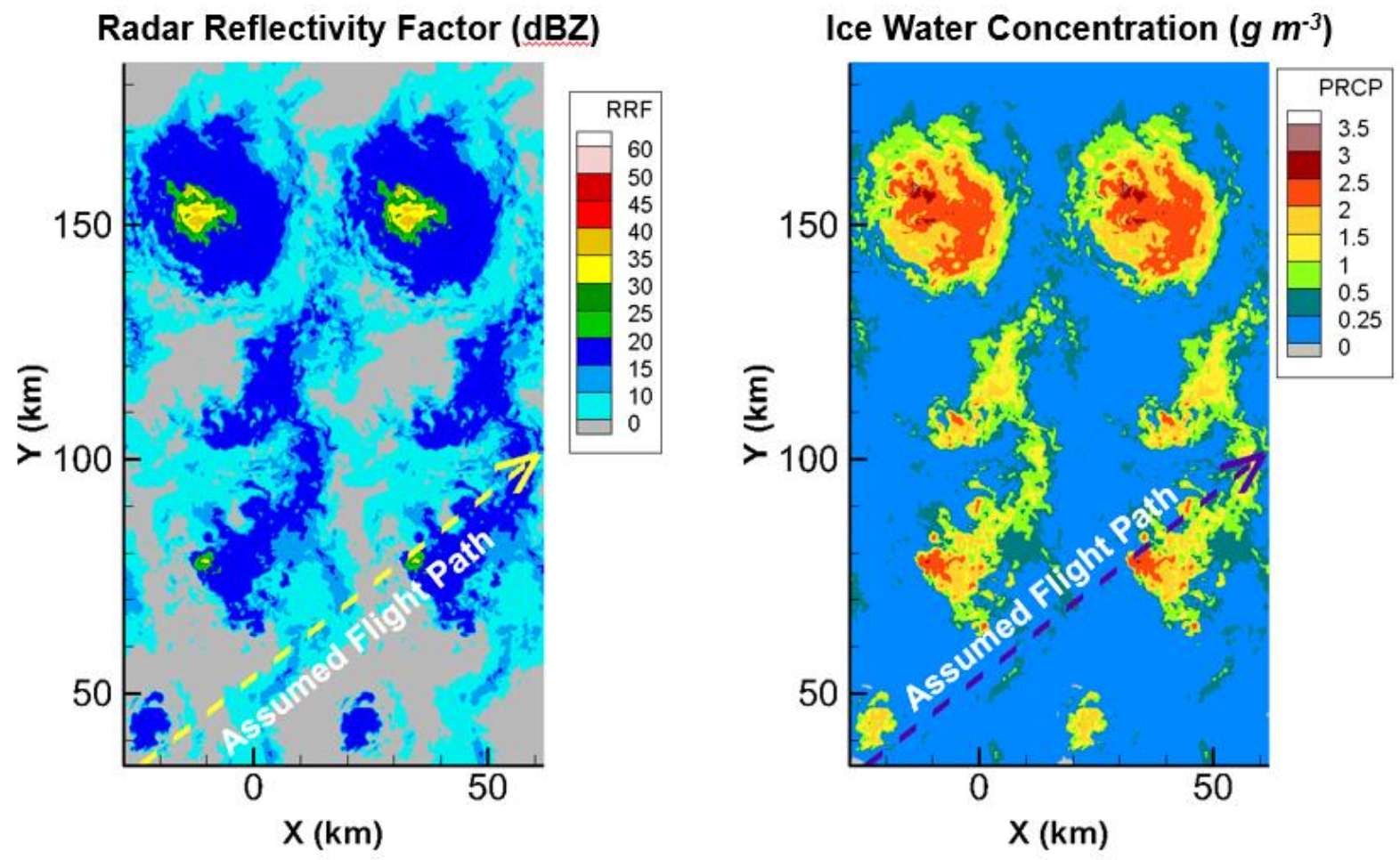

Figure 15. Same as Fig. 14, but at 10,335m (flight level $34 \mathrm{kft}$ ). 

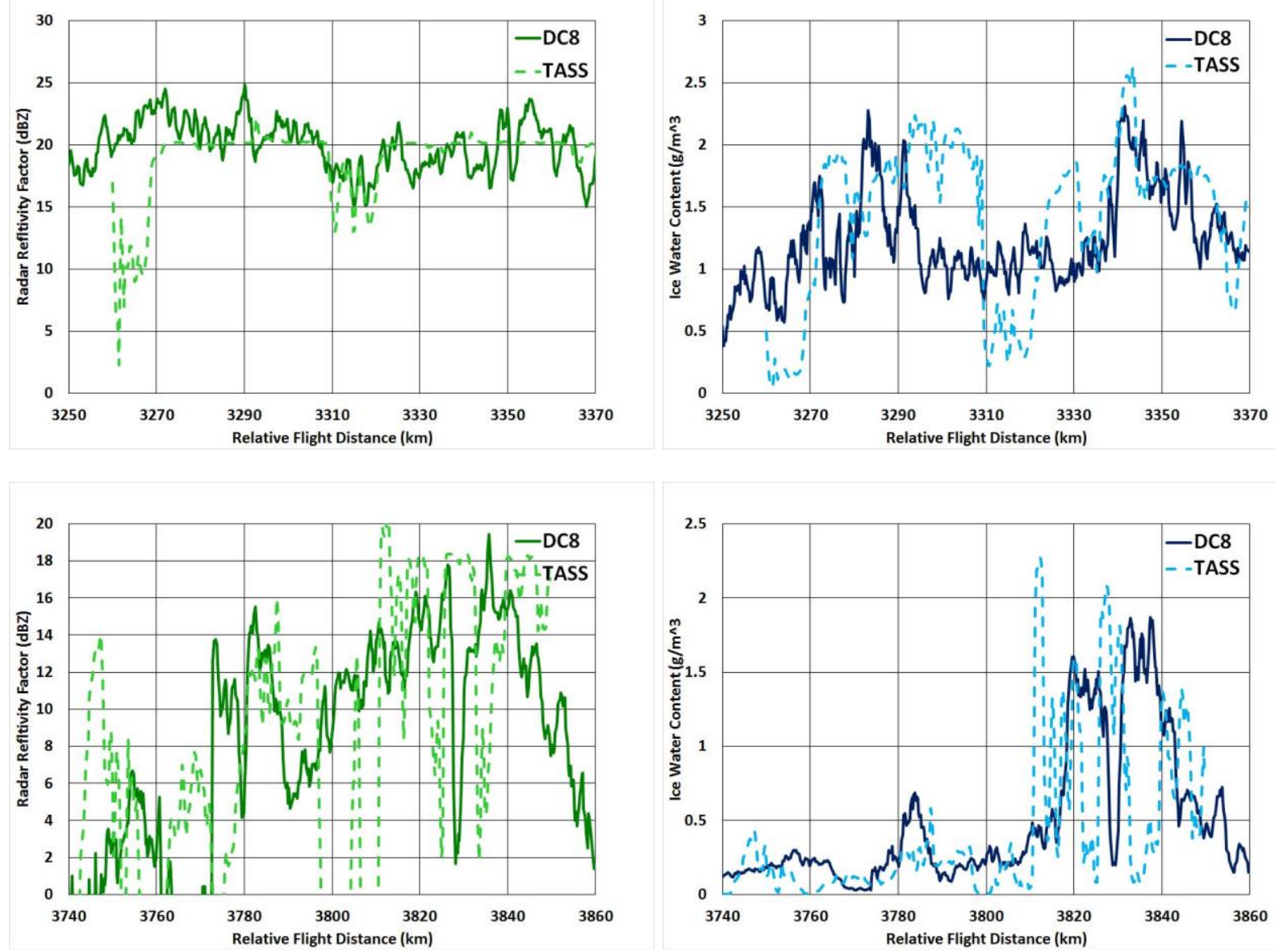

Figure 16. Comparison of RRF and IWC extracted along flight profiles shown in Figs. 14 and 15 (dashed lines) with those measured by the DC-8 (solid lines). Top row at an altitude of $8850 \mathrm{~m}$, bottom row at $10,350 \mathrm{~m}$.

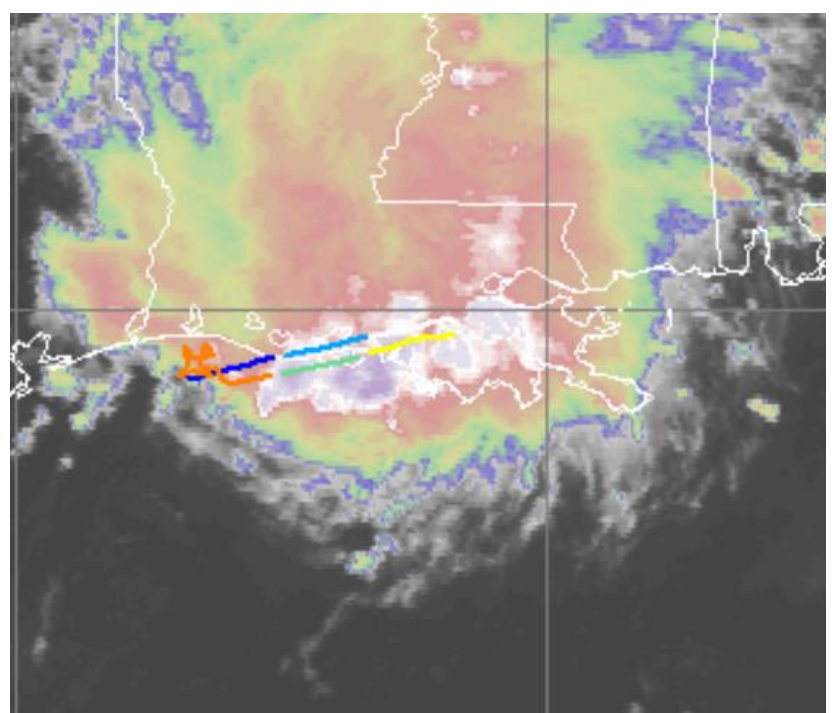

Figure 17. Two of the DC-8 legs with longest duration of IWC. Track of DC-8 superimposed on 1645 UTC GOES-13 Infrared satellite imagery (Courtesy NASA Langley Satellite Group).

American Institute of Aeronautics and Astronautics 

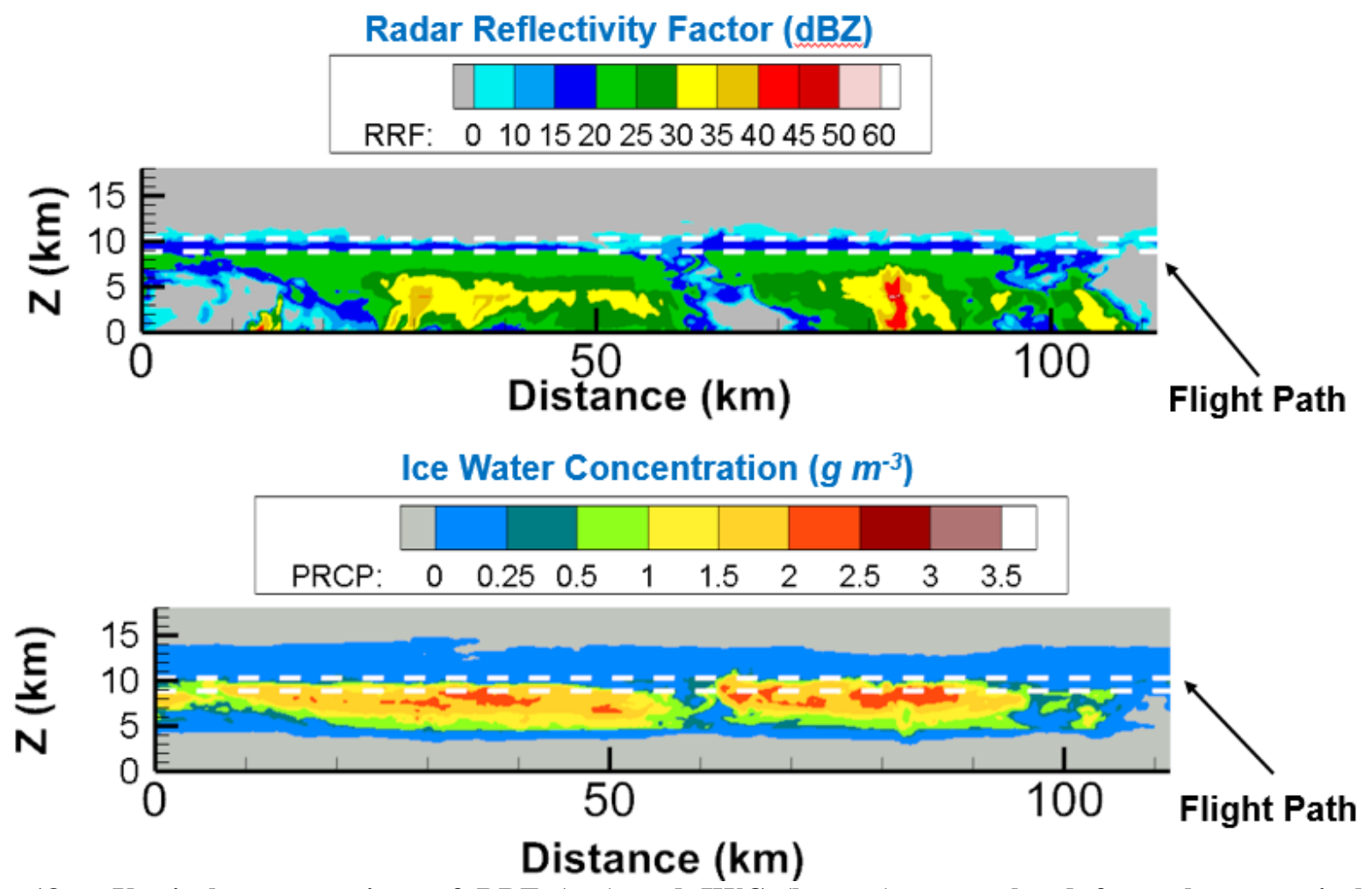

Figure 18. Vertical cross sections of RRF (top) and IWC (bottom) extrapolated from the numerical simulation along the flight profile shown in Fig. 14. Vertical position of both flight paths shown by dashed line. Altitudes are AGL.

The numerical simulation does not capture the region of stratified precipitation that lies downstream from the inflowing convective lines. However, the DC-8 flights did not encounter regions of HIWC when they overflew this region. It appears likely that the rain in this area was produced by moisture from the dissipation of the convective cells and the overrunning of the cool surface dome by the moist southerly air currents. A next-generation simulation would need to include the horizontal variation of temperature and wind into the simulation in order to capture these effects.

\section{Numerical Simulation of Continental Supercell Hailstorm}

In this section, the numerical simulation of a continental supercell hailstorm is presented. The purpose of this simulation is to validate the robustness of the microphysics used in TASS, and better understand differences in HIWC production between continental supercell storms and subtropical MCS convection. Validation parameters include: 1) production of large hail, 2) size of hail swath, 3) radar bounded weak echo region, 4) supercell features, 5) storm motion, 6) size and intensity of quasi-steady updraft, 7) size and maximum value of radar echo, and 8) duration. In this simulation, we will verify the validity of the simulation by comparing our solutions with observed data. In addition, this case will be analyzed for its potential in producing HIWC and compared with the previous case of summertime coastal convection.

This case has been simulated in the past with one of the first versions of TASS using a relatively coarse mesh. Even at this earlier stage of TASS development, the simulation was able to capture many of the storm's observed features. ${ }^{59,34}$

\section{A. Description of Observed Case}

On 2 August 1981, a very large and severe hailstorm moved across Southeastern Montana. The storm was observed during its mature phase with ground-based Doppler radars and with research aircraft, as it moved through a network of field instruments during the Cooperative Convective Precipitation Experiment ${ }^{60}$ (CCOPE). The storm quickly developed many classical features of a supercell hailstorm. It veered to the right of the environmental winds, and persisted for over 5 hours while leaving a wide swath of hail. The storm was reported to have: an intense quasi-steady updraft with cyclonic rotation, a low-level radar hook echo signature, a mid-level bounded weak echo region (BWER) signature (same as radar echo vault), damaging winds, a broad swath of 1-3 cm diameter hail with some sizes as large

American Institute of Aeronautics and Astronautics 
as $10 \mathrm{~cm}$, a mesolow or mesocyclone with a peak pressure drop of at least $6 \mathrm{mb}$, and a peak RRF between $65-75$ $d B Z .^{61,62,63,64}$ The primary updraft of the storm was reported to be over $14 \mathrm{~km}$ wide, and was located within the BWER. A research aircraft flew within the updraft at an altitude between $6 \mathrm{~km}$ and $7.5 \mathrm{~km}$ MSL; they found nearly adiabatic conditions, with updraft speeds greater than $50 \mathrm{~m} \mathrm{~s}^{-1}$, liquid water droplet concentrations of up to $6 \mathrm{~g} \mathrm{~m}^{-3}$, and the absence of precipitation-sized particles. ${ }^{65}$ The lack of larger particles explained the very low magnitudes of RRF within the BWER. Hail was penetrated by the research aircraft on the western edges of the updraft in association with the high reflectivity regions. Weisman et al. ${ }^{66}$ reported that the storm produced at least one funnel cloud and that some damage reports were "suggestive" of tornadic activity. Surface wind speeds were estimated between 50 to $100 \mathrm{mph}$ $\left(20\right.$ to $\left.45 \mathrm{~m} \mathrm{~s}^{-1}\right){ }^{63}$

A special rawinsonde sounding was launched near the storm (Fig. 19) and indicated an environment very favorable for intense convection. Convective indices calculated from the sounding exhibited a CAPE of almost $3500 \mathrm{~J} \mathrm{~kg}^{-1}$ and a lifted Index of $-10^{\circ} \mathrm{C}$. The sounding also indicated a tropopause height of $10.9 \mathrm{~km}$ MSL ( 9.9 km AGL) with a temperature of $-47.5^{\circ} \mathrm{C}$, and an equilibrium level at $198 \mathrm{mb}(12.3 \mathrm{~km}$ MSL) with a temperature of $51.7^{\circ} \mathrm{C}$. According to the both the sounding and aircraft observations, the cloud base temperature and height were about $13.6^{\circ} \mathrm{C}$ and $2.6 \mathrm{~km}$ MSL, respectively. ${ }^{63}$ The ground was slightly less than $1 \mathrm{~km}$ above sea level and varied somewhat with location. The wind profile for the sounding exhibited a strong magnitude of helicity ${ }^{67,68}$ and vertical shearing of the environmental wind. High values of both helicity and CAPE are indicative of supercell and tornadic storm environments. The presence of dry environmental air at storm midlevels likely inhibited any strong tornado formation (e.g., Proctor et al. ${ }^{33}$ )

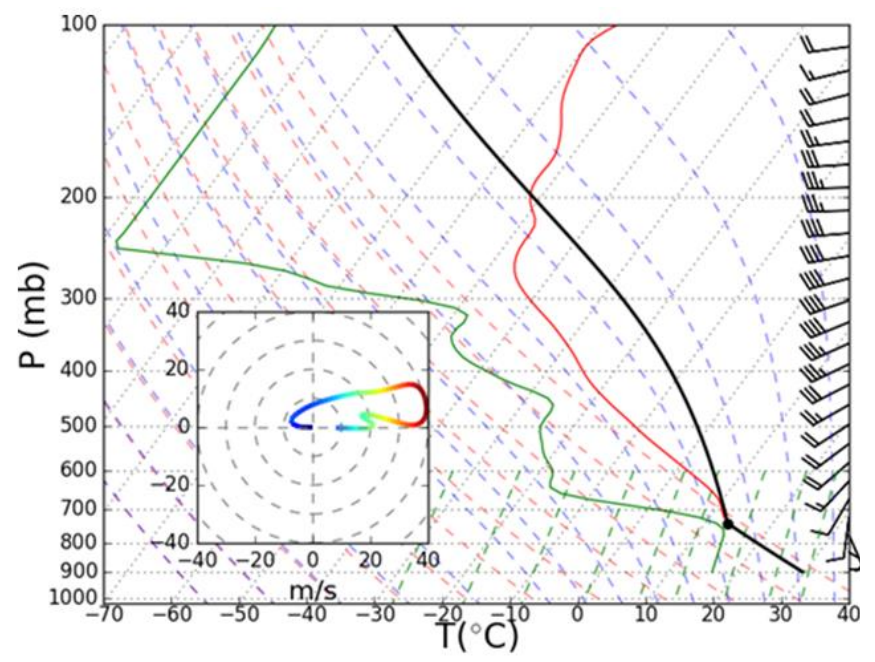

Figure 19. Skew-T diagram representing environment for 2 August 1981. Special sounding observed near Knowlton MT, at 2356 UTC. Environmental wind hodograph inserted at bottom left.

\section{B. Configuration}

In numerical modeling of this system, we apply the same version of the TASS model as in the Coastal-MCS case. Differences are only due to grid and domain configuration, boundary conditions, input sounding, and several input parameters that define the continental aspects of the cloud droplets and the hail size distribution. All are discussed below.

The domain is size is defined to be $150 \mathrm{~km} \times 150 \mathrm{~km}$ in the horizontal and $20 \mathrm{~km}$ in the vertical (Table 7). An evenly spaced grid size of $200 \mathrm{~m}$ is assumed. Open lateral boundaries conditions are applied at all lateral boundaries. The ground surface is assumed flat and no terrain features are included. The domain uses the TASS model's internal tracking algorithms ${ }^{17}$ in order to move the grid with the lateral translation of the storm.

The initial state profiles for temperature, pressure, wind, and humidity are horizontally uniform but vary vertically according to the input sounding shown in Fig. 19. Values representative of contental Great-Plains systems are assumed to for the cloud droplet concentration and for the hail size distribution intercept parameter (Table 8).

Table 7. Domain Size and Resolution

\begin{tabular}{|l|l|}
\hline Domain Parameter & Physical Dimension \\
\hline Lateral dimensions $(\mathrm{X}, \mathrm{Y})$ & $\mathbf{1 5 0} \mathrm{km} \times 150 \mathrm{~km}$ \\
\hline Vertical dimension (Z) & $20 \mathrm{~km}$ \\
\hline Lateral grid spacing & $200 \mathrm{~m}$ \\
\hline Vertical grid spacing & $200 \mathrm{~m}$ \\
\hline Computational grid & $\sim 56 \times 10^{6}$ grid points \\
\hline
\end{tabular}

\section{Table 8. Initial Parameters}

\begin{tabular}{l} 
Cloud base height (AGL) \\
\hline Cloud droplet number density, $N_{c d}$ \\
\hline $\begin{array}{l}\text { Hail/Graupel particle size } \\
\text { distribution intercept, } N_{\text {oh }}\end{array}$
\end{tabular}
$1700 m(740 m b)$ 800 droplets $\mathrm{cm}^{-3}$ $2 \times 10^{4} \mathrm{~m}^{-4}$

American Institute of Aeronautics and Astronautics 
The major diffences between the initial conditions of this case and the coastal MCS case, are that this case represents a more continental environment with stronger vertical wind shear, less moisture, but greater instability.

\section{Comparison of Simulation with Observations}

The numerical simulation is initiated at time zero by introducing a thermal impulse and integrating over 4 hours of time. The simulation produces a supercell hailstorm and captures many of the features observed in the real storm. These include: large hail, wide hail swath, funnel cloud with damaging surface wind, $15 \mathrm{~km}$ wide quasi-steady updraft surrounded at storm-mid-level by a radar echo vault or BWER, a radar hook echo signature, right-rear quadrant gust front, massive overshooting tops, and a large spreading anvil. As can be see in Table 9, scales and intenisties match very well between the observed and simulated event. The simulated updraft velocity at $6.5 \mathrm{~km} \mathrm{MSL} \mathrm{of} 55 \mathrm{~m} \mathrm{~s}^{-1}$ matches the peak value measured by a research aircraft that penetrated the storm at the same level. As found from the aircraft measurments, the updraft core was nearly adiabatic with little or no precipitation. The model simulation, as in the observational studies, found most of the hail to be on the western and nortwestern edges of the primary storm updraft.

Table 9. Comparison of observations with TASS for 2 August 1981 Supercell Hailstorm

\begin{tabular}{|c|c|c|}
\hline Features & Observed & TASS Simulated \\
\hline $\begin{array}{l}\text { Anvil Extent Downstream from Updraft } \\
\text { (based on Radar Echo) }\end{array}$ & $>200 \mathrm{~km}$ & $>150 \mathrm{~km}$ \\
\hline Anvil Extent Upstream from Updraft & $>20 \mathrm{~km}$ & $>60 \mathrm{~km}$ \\
\hline BWER Diameter & $\sim 7.5 \mathrm{~km}$ & $\sim 8 \mathrm{~km}$ \\
\hline BWER Vertical Extent & $10 / 7.5 \mathrm{~km} \mathrm{MSL}$ & $12-14 \mathrm{~km}$ MSL \\
\hline Gust Front Location & SW Flank & SW Flank \\
\hline Peak Gust Front Wind Speed & $>20 \mathrm{~m} / \mathrm{s}$ & $25 \mathrm{~m} / \mathrm{s}$ \\
\hline Typical Hail Diameter at Surface & $1-3 \mathrm{~cm}$ & peak median diameter: $2 \mathrm{~cm}$ \\
\hline Hail Shaft Location Relative to Center of BWER & 3-4 km West & 4-6 km WNW \\
\hline Width of Hail Swath & $20-30 \mathrm{~km}$ & $22.5 \mathrm{~km}$ \\
\hline Supercell Lifetime & $>5$ hrs & $>4 h r s$ \\
\hline Persistent Low-Level Radar Hook Echo & yes & Yes \\
\hline Maximum Liquid Cloud Water Content & $6.5 \mathrm{~g} \mathrm{~m}^{-3}$ & $5.5 \mathrm{~g} \mathrm{~m}^{-3}$ \\
\hline Surface Pressure Drop & $6 m b$ & $\begin{array}{l}\text { Mesocyclone } 4 \mathrm{mb} / \\
\text { tornado: } 21 \mathrm{mb}\end{array}$ \\
\hline Peak Rainfall Accumulation & $30-35 \mathrm{~mm}$ & $25 \mathrm{~mm}$ \\
\hline Peak Radar Reflectivity Factor & $75 d B Z$ & $72.6 d B Z$ \\
\hline Storm Movement (development stage) & 260 at $10 \mathrm{~m} / \mathrm{s}$ & 250 at $12 \mathrm{~m} / \mathrm{s}$ \\
\hline Storm Movement (supercell stage) & 282 at $18 \mathrm{~m} / \mathrm{s}$ & 280 at $16 \mathrm{~m} / \mathrm{s}$ \\
\hline Storm Top Overshoot above EL & 3-4 km & $5 \mathrm{~km}$ \\
\hline Updraft Diameter & $14-17 \mathrm{~km}$ & $15 \mathrm{~km}$ \\
\hline Max Updraft Velocity at $6.5 \mathrm{~km}$ MSL & $53 \mathrm{~m} / \mathrm{s}$ & $55 \mathrm{~m} / \mathrm{s}$ \\
\hline Diameter of $20 \mathrm{dBZ}$ Echo at $12 \mathrm{~km}$ MSL & $45 \mathrm{~km}$ & $45 \mathrm{~km}$ \\
\hline Peak Surface-Level Gusts East of Updraft & $>25 \mathrm{~m} / \mathrm{s}$ & $30 \mathrm{~m} / \mathrm{s}$ \\
\hline Radar Echo Top & $16 \mathrm{~km} \mathrm{MSL}$ & $18 \mathrm{~km} \mathrm{MSL}$ \\
\hline Tornadoes & Funnel cloud sighted & $\begin{array}{l}\text { Yes, western side of } \\
\text { mesocyclone }\end{array}$ \\
\hline Peak Surface Wind / Damage & $\begin{array}{l}\text { F1- wind damage } \\
\text { (estimated } 33-50 \mathrm{~m} / \mathrm{s} \text { ) }\end{array}$ & $56 \mathrm{~m} / \mathrm{s}$ \\
\hline Maximum Altitude of $10 \mathrm{dbZ}$ Contour in BWER & $6-8 \mathrm{~km} \mathrm{MSL}$ & $6.5 \mathrm{~km} \mathrm{MSL}$ \\
\hline
\end{tabular}


Supercell environments often produce tornadoes or familes of tornadoes, and a funnel cloud with surface wind damage was reported with this system. The funnel cloud that was produced in the numerical simulation was intermittent and dissiapted when it moved into the cooler dryer air underneath the hail and rain shafts. Tornado formation in this simulation showed similar characteristics to those studied in an earlier paper, where the presence of dry mid-level air acts to weaken or suppress tornado formaition in supercell environments. ${ }^{33}$

The time evolution of the area with RRF greater than $55 \mathrm{dBZ}$ at an elevation of $5 \mathrm{~km}$ MSL (blue) and the peak RRF anywhere in the storm (red) is shown in Fig. 20. The peak RRF from the simulation matches the observations very well. For the area with RRF greater than $55 \mathrm{dBZ}$, both observation and TASS show a ramp up in the first two hours of the storm's lifetime, but the simulation shows this area to be smaller than detected by ground-based radar.

A comparison of the supercell structure from TASS with measurements from ground-based radar are shown in Figs. 21 and 22. Two horizontal levels of RRF are shown, one at $10 \mathrm{~km} \mathrm{MSL}$ and the other at 4 $\mathrm{km}$ MSL. The TASS simulation reproduces many of the observed features and supercell signatures, including the BWER (i.e. radar echo Vault (V)), the radar hook echo, and the radar echo streamer. The scale of the area covered by each intensity of RRF are similar between TASS and observed as well. One contrast however, is that the highreflectivity area within the hook echo region appears larger in the observation than in the simulation. The area of highest reflectivity, which is west and northwest of the BWER, is associated with large hail in both observation and simulation.

In Fig. 23, a vertical cross-section along $x-z$ coordinates is taken through the middle of the BWER. Again both the simulation and observation show: similar features, similar intensities, and similar spatial scales. The BWER, or radar Vault, is clearly present in the simulation and extends deep into the storm. The BWER is located within the intense storm updraft and is produced by a lack of significant precipitation-sized particles.

\section{HIWC Characteristics in Simulated Storm}

The Montana supercell with its quasi-steady, large diameter, and intense updraft, generates large volumes of ice crystals that are transported into the upper regions of the troposphere. Increasing wind speeds with height, which is a characteristic of supercell environments, quickly transports many of the ice particles downstream within a large expanding anvil cloud. Hail and larger ice particles are also carried up to high altitudes by the strong updrafts, but fall out relatively close-by due to their significant fall velocities. Therefore, large values of RRF can be found at storm upper-levels within proximity to the supercell updraft. The RRF drops-off with distance from the updraft, as the larger particles fall out and the remaining smaller particles are carried downstream.

A graphical representation of the cloud and precipitation fields from TASS is show in Fig. 24. Overshooting tops, which are above the predominant supercell updraft, can penetrate several kilometers into the stratosphere. A large anvil cloud spreads mostly downstream from the overshooting tops due to the strong westerly winds beneath the tropopause (cf. Fig. 9). This anvil cloud covers many square kilometers, and forms a large overhang of cloud material downstream from the storm updraft. Due to the intensity of the updraft, some the anvil material is transported counter to upper-level winds, and produces a forward overhang upstream from the storm updraft.

The coldest cloud tops (Fig. 25) are associated with the overshooting tops above the intense storm updraft. Cloud tops at temperatures/heights near the equilibrium level, expand over a large area downstream from the overshooting tops. Obviously in Fig.25, the anvil expands northeastward, beyond the boundaries of the model domain.

American Institute of Aeronautics and Astronautics 


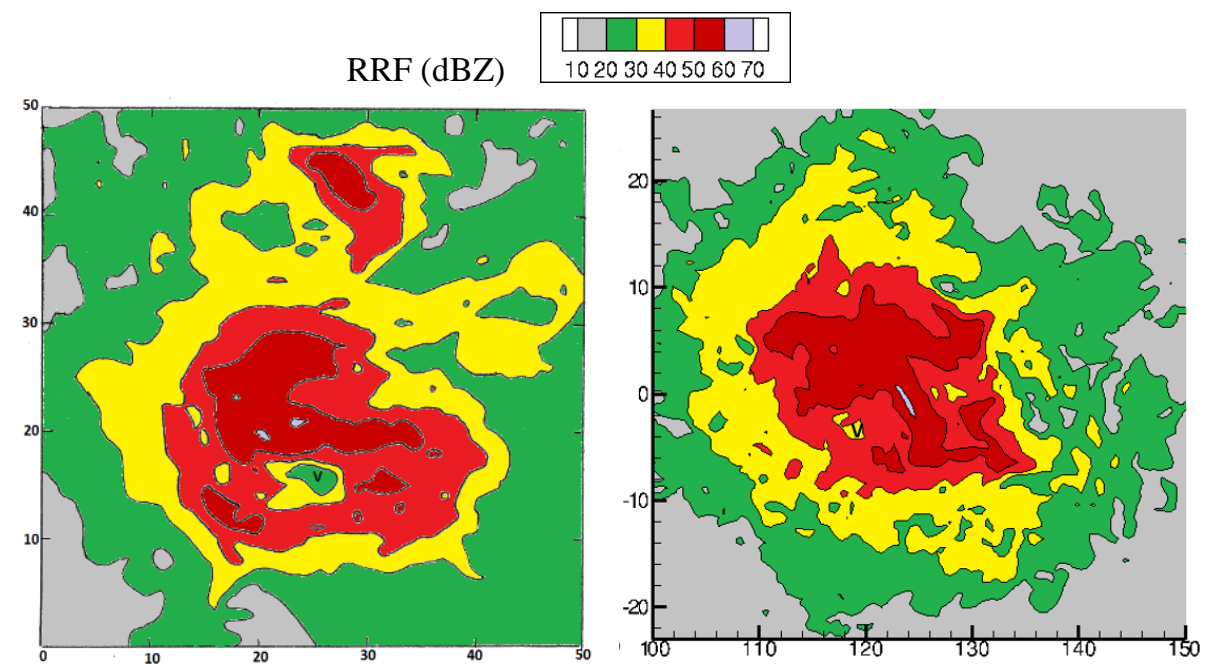

Figure 21. Horizontal cross-section of Radar reflectivity factor at an altitude of $10 \mathrm{~km}$ MSL. Left adapted from Miller's analysis of ground based Doppler radar; ${ }^{62}$ right from TASS at $t=3 \mathrm{hr}: 07 \mathrm{~min}$. Both plots windowed to $50 \mathrm{~km} \times 50 \mathrm{~km}$ area with major tick every $10 \mathrm{~km}$. The Radar echo Vault or BWER identified with $\mathrm{V}$.
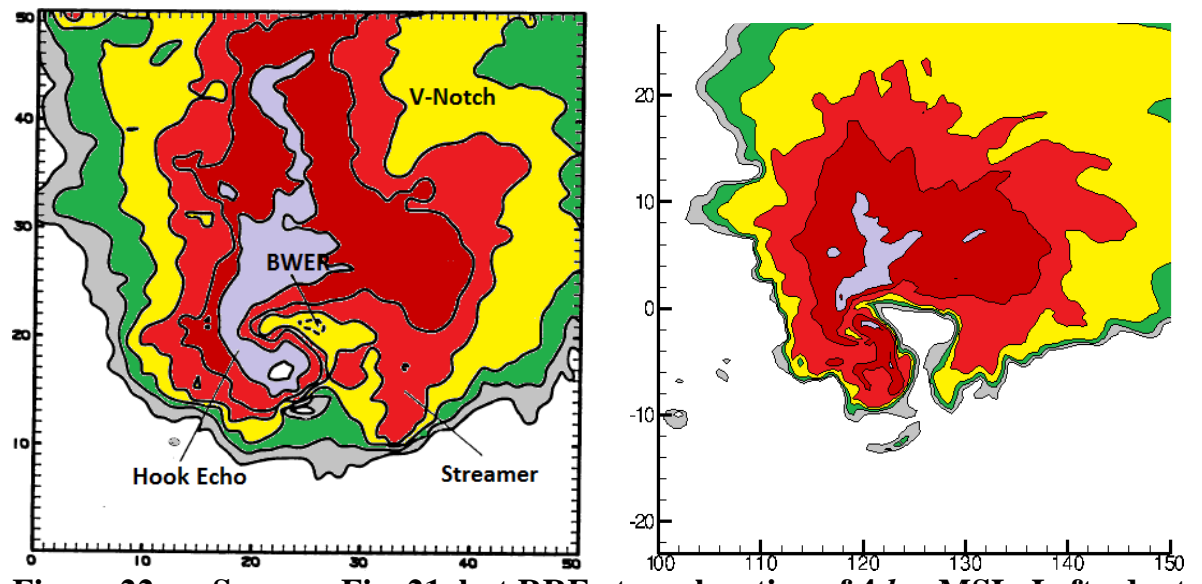

Figure 22. Same as Fig. 21, but RRF at an elevation of $4 \mathrm{~km}$ MSL. Left adapted from Miller's analysis of ground based Doppler radar; right from TASS at $t=3 \mathrm{hr}: 07 \mathrm{~min}$.
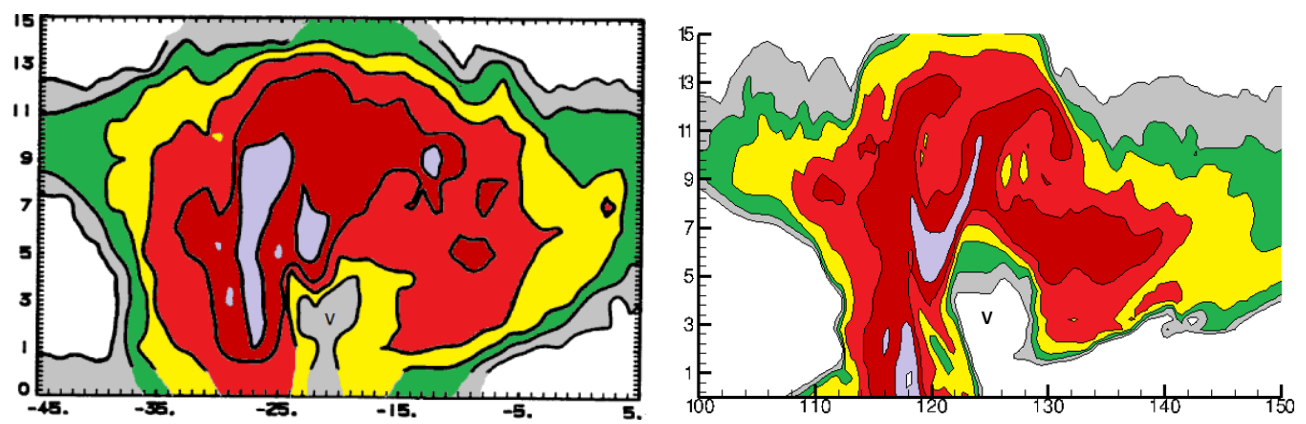

Figure 23. Same as Fig. 21, but RRF along vertical west-east cross-section through BWER. Left adapted from Miller's analysis of ground based Doppler radar; right from TASS at $t=3 \mathrm{hr}: 07 \mathrm{~min}$. Altitude in $\mathrm{km}$ AGL with major ticks every $1 \mathrm{~km}$ along abscissa. 


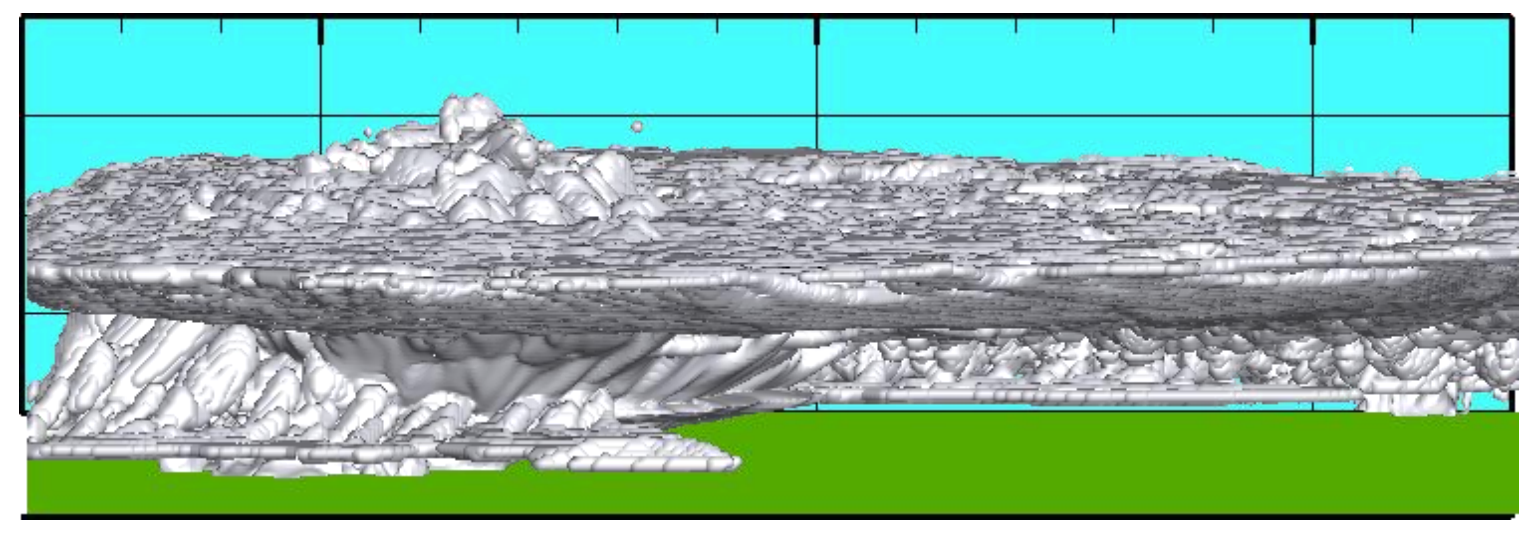

Figure 24. Simulated cloud and precipitation surfaces within the full TASS domain. Viewed from south.
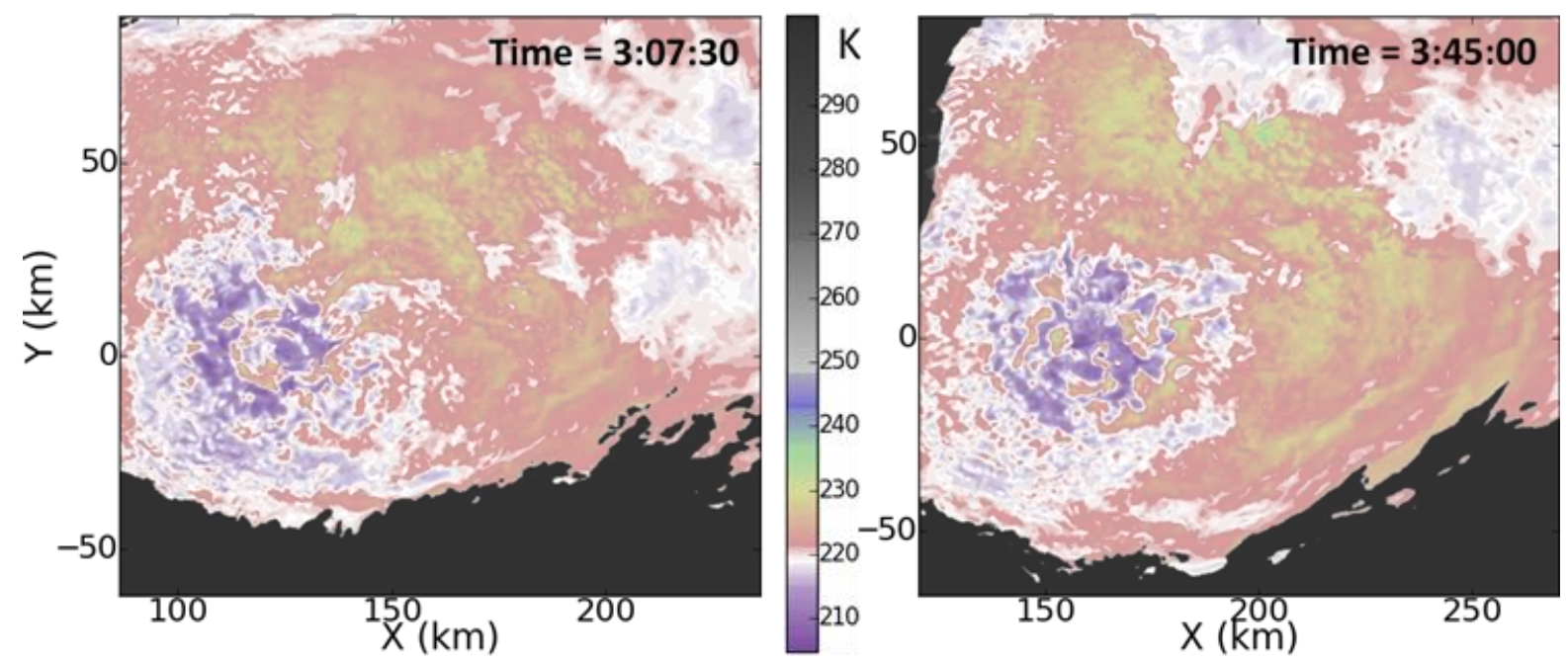

Figure 25. Cloud top temperatures from TASS at 3hr:7.5 min (left) and 3hr:45min (right) simulation time. Coldest temperatures associated with overshooting tops in southwestern quadrant of figure.

Very similar features for the simulated Montana supercell storm can be seen in the observed visible satellite imagery of the actual system (Fig. 26). The overshooting tops are positioned near the southern end and the anvil expands toward the north-northeast. The horizontal dimension of the observed cloud anvil compared with the cloud top depicted in Fig. 25 are nearly identical.

Figure 27 shows the simulated IWC and RRF along a horizontal cross-section taken at 10km MSL (9km AGL). The size and shape of the system represented in the cross-section is consistent with the satellite imagery in Fig. 26. In Fig. 27, most of the RRF greater than $20 \mathrm{dBZ}$ is confined to area within a $50 \mathrm{~km}$ diameter centered about the primary updraft and BWER. Values of RRF between 15-20 dBZ cover large areas downstream for the overshooting tops. Figure 27 also shows vast areas with IWC greater than $1 \mathrm{~g} \mathrm{~m}^{-3}$. In fact, areas with $1 \mathrm{~g} \mathrm{~m}^{-3}$ or greater can be found at distances of up to 50 to $100 \mathrm{~km}$ away from the regions with the greatest storm RRF. Our simulation seems to imply that by avoiding the high reflectivity areas by 20 nautical miles $(37 \mathrm{~km}$ ), may not be sufficient for avoiding prolonged HIWC exposures. 
To further explore the structure of the simulated storm, vertical cross-sections are extracted alone lines A-B and C-D that that appear in Fig.27. These cross sections are shown in Figs. 28 and 29. They also help illustrate where HIWC conditions may be found relative to the storm.

The cross-sections through A-B (Fig. 28) are taken northeastward through the storm updraft. It shows strong reflectivity surrounding the BWER and extending to the upper levels of the storm. High levels of IWC, largely composed of hail, are brought to the ground on the southwestern side of the storm updraft and at upper-levels surrounding the updraft. Aircraft routinely avoid these areas due to their high values of RRF. More of a factor to air traffic is that significant levels of IWC that can be found over large areas within the cloud canopy, at great distances downstream from the storm's high reflectivity regions. Furthermore, the RRF within the canopy are very low and could be undetectable with many airborne weather radars.

In Fig. 29, a cross section is taken orthogonal to the direction of the shearing anvil. It is taken northwestward between $\mathbf{C}$ and $\mathbf{D}$ along the edge of the areas with significant IWC (Fig. 27). This cross-section resides at least $70 \mathrm{~km}$ or more from areas with high RRF. Along this cross section, IWC greater $1 \mathrm{~g} \mathrm{~m}^{-3}$ can be seen to extend for over a $100 \mathrm{~km}$ length. The layer has a thickness that is several kilometers thick. This layer also consist of very weak RRF ( $20 \mathrm{dBZ}$ ), and

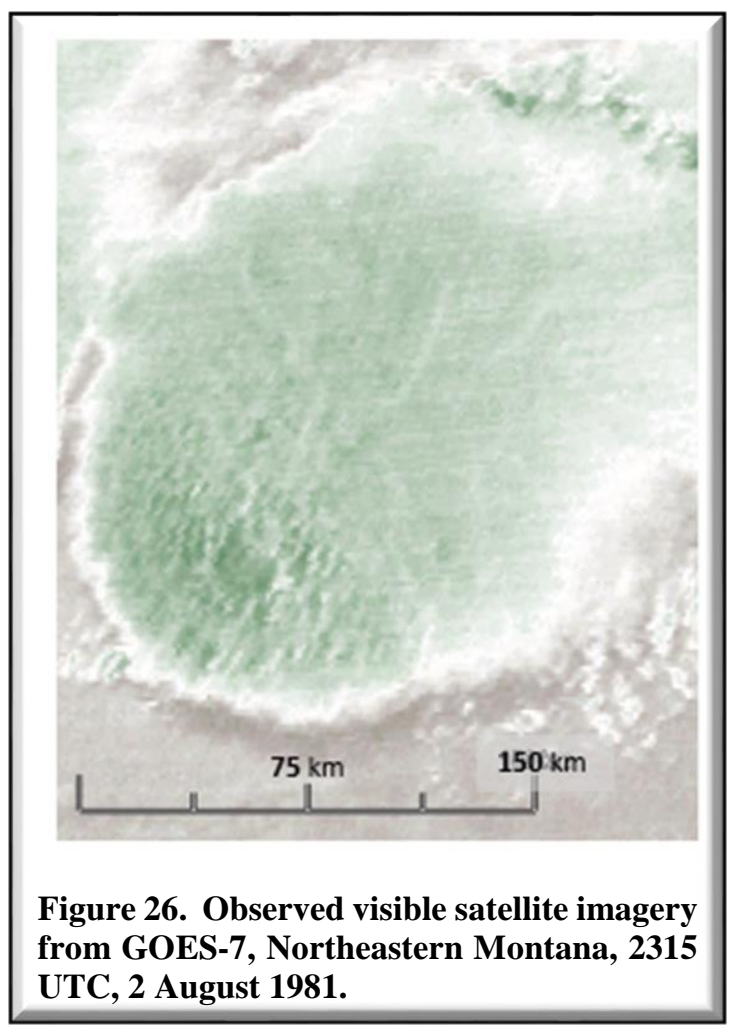
underneath has no detectable radar reflectivity or precipitation.

Both cross-sections show that a layer with HIWC can extend over large distances and with very weak RRF. Beneath this layer containing HIWC, precipitation was rarely apparent and radar reflectivity not detectable. One visual queue sometimes recommended to pilots for helping to identify potential HIWC conditions is the presence of strong to moderate RRF from rain beneath regions of HIWC. This queue would not apply to a supercell storm such as this.

This case of a continental supercell also demonstrates that HIWC risks may not be confined to just oceanic and coastal MCS, since regions of significant IWC may extend for large distances with little RRF.

\section{Discussion and Conclusion}

Flight data and results from numerical simulations are analyzed to better characterize the HIWC threat for aircraft, and to improve our understanding of the relationship between HIWC, radar, and satellite signatures. Flight measurements with airborne radar and microphysical probes suggest that RRF alone may not be adequate for the detection of HIWC conditions. This fact also is reinforced from the numerical model simulations.

The numerical simulations confirm that HIWC can be produced in contrasting environments. In warm, moist, coastal and oceanic environments, large volumes of ice crystals can be pumped into the upper-troposphere by regenerating convective plumes associated with a long-lasting system. Cloud material carried in the upper-level outflow from these plumes coalesces to form a large overhanging canopy, and contain significant concentrations of ice crystals. Perhaps, due to the weaker wind shear of these environments and the duration of the systems, large concentrations may accumulate over time.

Our simulation of a large continental supercell shows it to have a large, persistent, and nearly adiabatic updraft that also can pump large volumes of ice crystals in to the upper troposphere. Vertical windshear with strong winds aloft (which are an ingredient in producing supercells) can act to transport ice crystals over large areas. We speculate that the increase ventilation due to environmental wind shear may dilute the peak concentrations of IWC in supercells.

American Institute of Aeronautics and Astronautics 

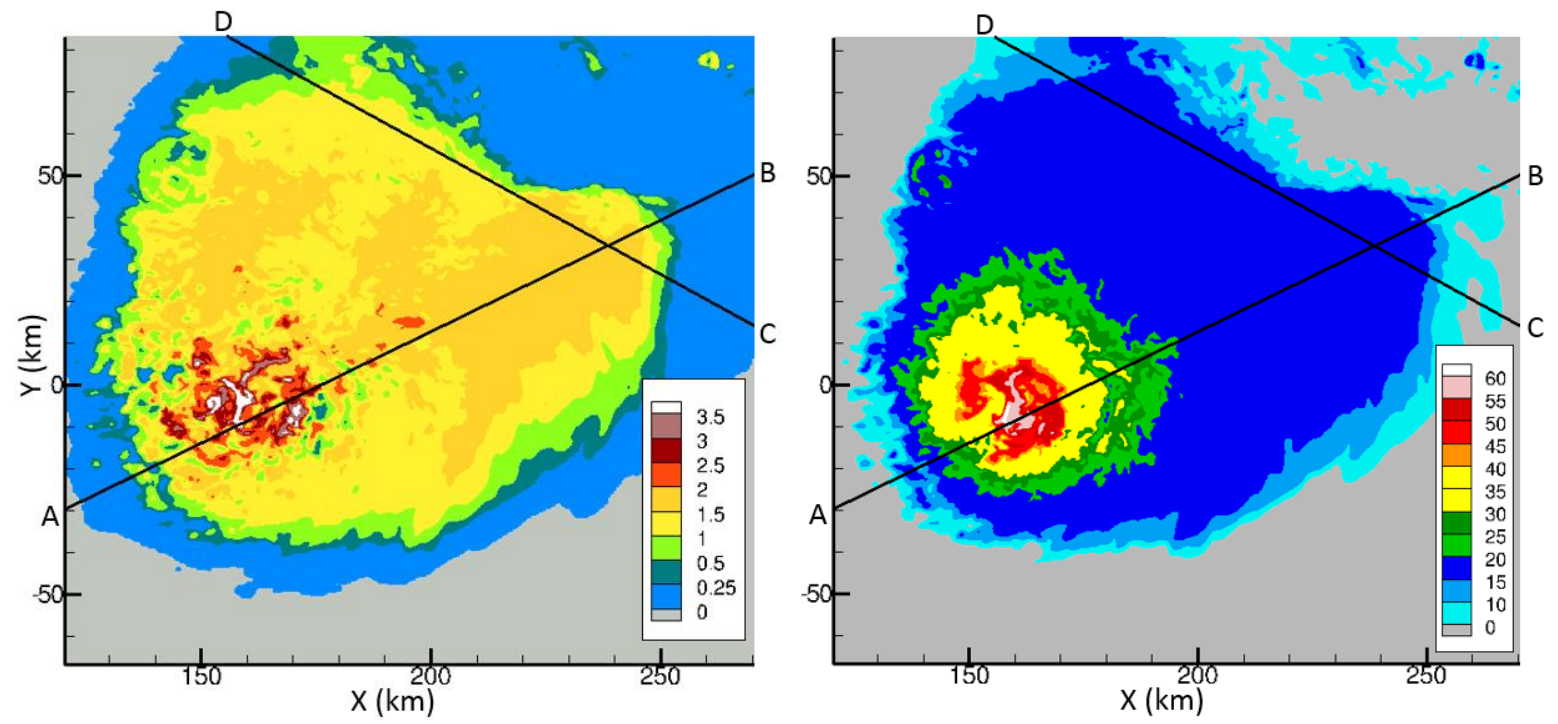

Figure 27. Ice water content (left) and RRF (right) from TASS at an elevation of $10 \mathrm{~km}$ MSL and $3 \mathrm{hr}: 45$ min) simulation time. Ice water content $\left(\mathrm{g} \mathrm{m}^{-3}\right)$ is sum of ice crystal, snow, and hail water content. Units for RRF are $(d B Z)$.
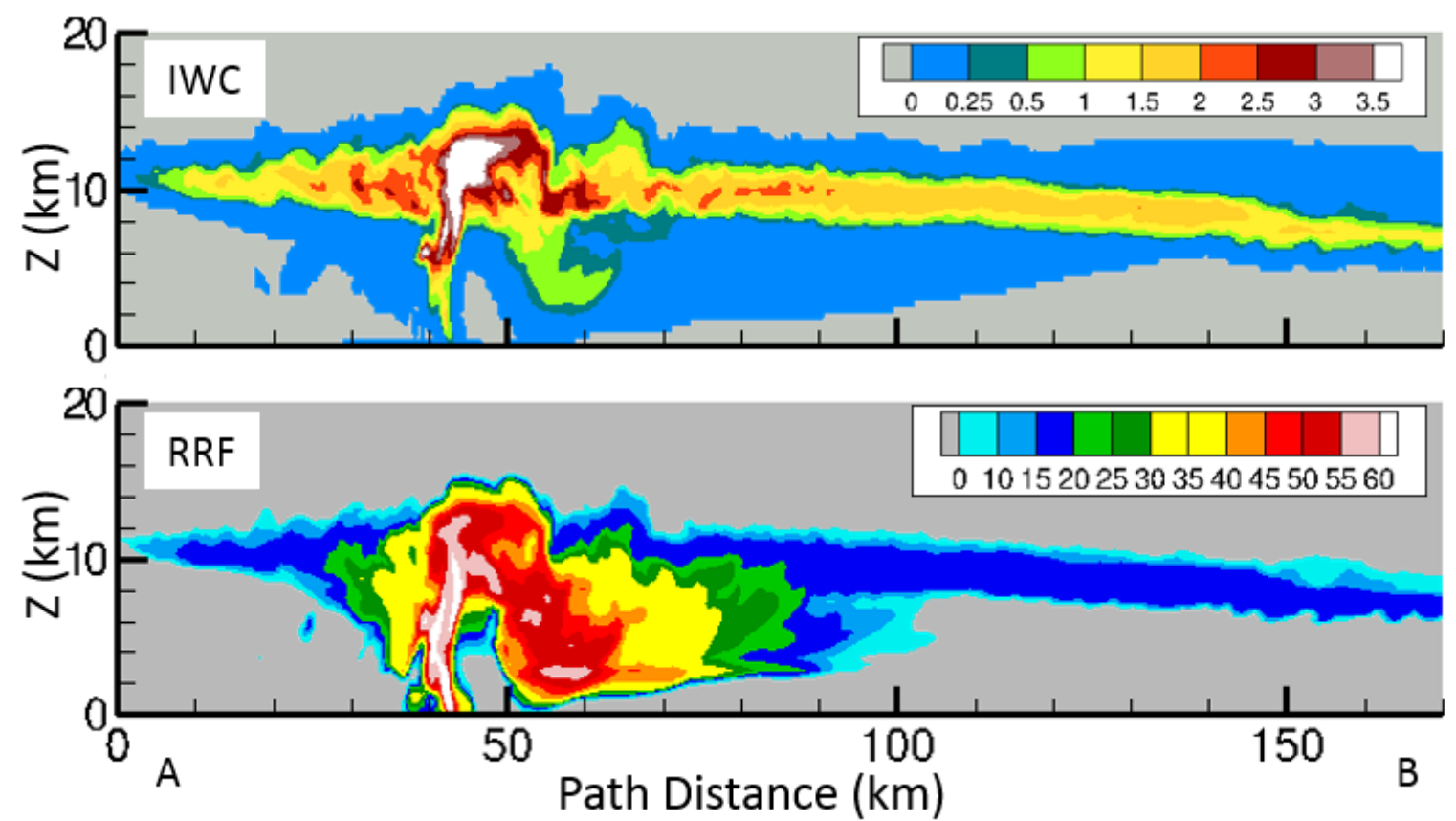

Figure 28. Vertical cross section along A-B in Fig. 27. Top is ice water content $\left(\mathrm{g} \mathrm{m}^{-3}\right)$ and bottom is RRF $(d B Z)$. Altitudes are above ground level. 

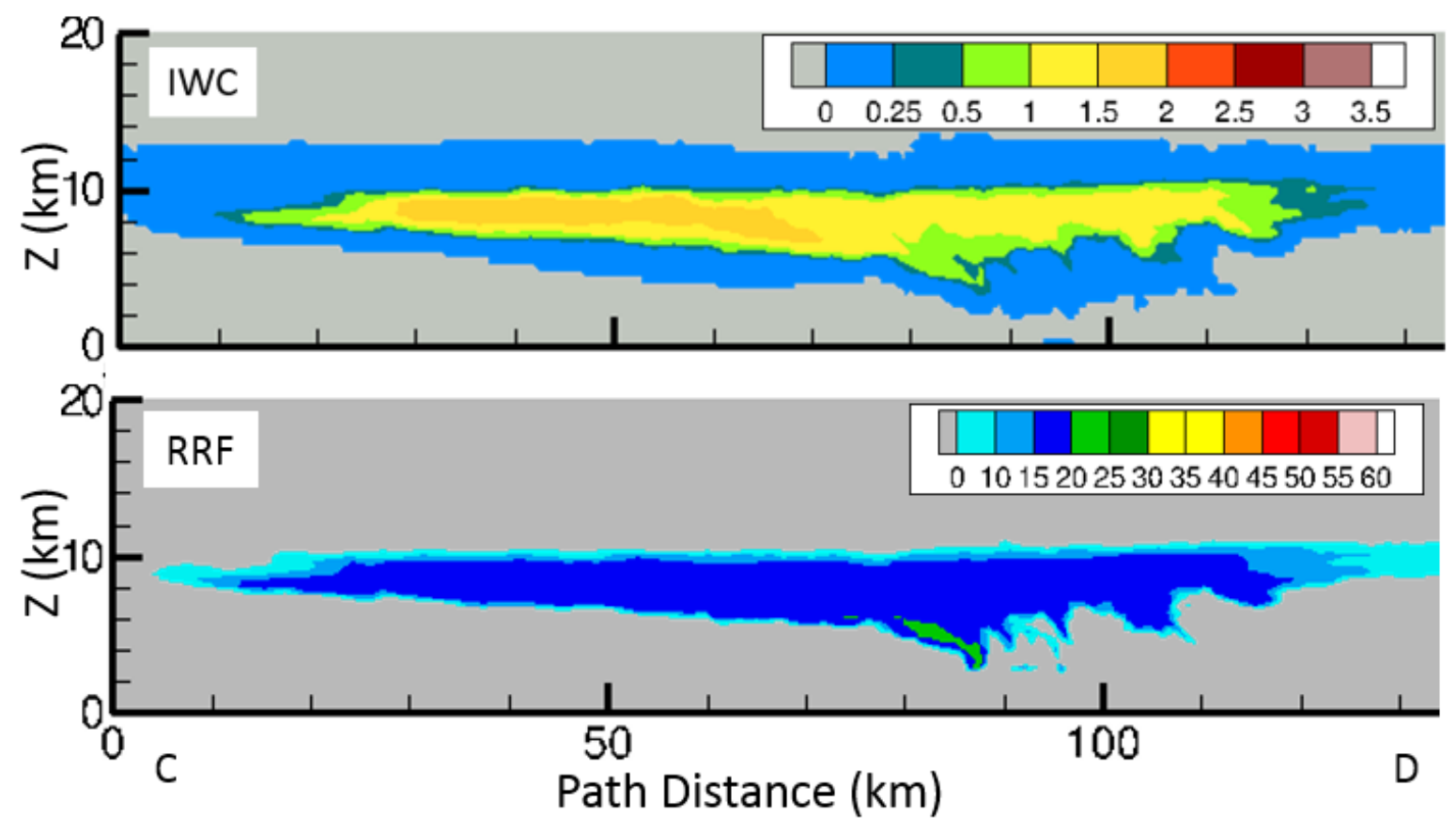

Figure 29. Same as in Fig. 28, but for position C-D in Fig. 27.

In our study, the microphysics for snow is improved by using analyzed PSD data measured during the flight campaign. A new relationship is developed that relates the exponential size-distribution intercept for ice particles with their water content. In the past, the value for the intercept has been assumed constant or a function of temperature only. The new relationship is a function of snow or ice water content, as well as temperature, and was used to improve the microphysical submodels in TASS.

The TASS model was then applied to contrasting types of convection and compared to available observations. This comparison seemed very good and demonstrated the model could be applied robustly to convection in different types of environments. Excellent results were achieved using only simple bulk parametrizations for microphysics; suggesting that models that are more complex may not be needed, depending upon application. The profiles of ice water content and RRF extracted from the simulation compared reasonably well with the measurements by the DC-8, during penetrations of the coastal MCS; .although, some differences in variability were noted. The TASS model was also used to simulate a specific supercell hailstorm, with excellent comparison to measurements, in terms structure, features, scales, and magnitudes.

The numerical studies for both cases found that regions of significant IWC could extend above regions with little or no RRF. This would imply that moderate to high radar reflectivity might not always be underneath HIWC events.

Yet to be investigated is the potential for HIWC detection using a combination of sensors and sources for information (i.e. satellite and other weather data.). Also unexplored is the ability to detect HIWC with advanced airborne radar tools.

\section{Appendix: Ice Crystal Size Distributions}

Relationships between the ice crystal size distributions, temperature, and ice water content are needed for the parameterization of microphysical submodels used in TASS. These relationships could be useful in other applications, such as the understanding the radar reflectivity factor (RRF) due to ice crystals. Dr. Alexei Korolev processed the particle size distribution (PSD) data ${ }^{69}$ from data collected at one-Hertz intervals during the DC-8 flights from a 2D-S probe and a particle-imaging probe (PIP). The measured data was discretized into appropriate size bins and normalized by the width of the corresponding bin. This allowed for the direct comparison of the PSD data with different size resolutions and common theoretical drop-size distributions (e.g. Marshall-Palmer ${ }^{70}$ ). The size resolution for the 2D-S probe was $10 \mu \mathrm{m}$ and $100 \mu \mathrm{m}$ for the PIP. The range of particle measurements extends from $15 \mu \mathrm{m}$ to $12.845 \mathrm{~mm}$. The

American Institute of Aeronautics and Astronautics 
size of irregularly shaped ice particles, as estimated from particle images, may be defined in several different ways. The composite PSD data used the length of the particle parallel to the photodiode array, commonly called $L y$.

An intercept $\left(N_{0}\right)$ and slope $(\lambda)$ parameter were found from the data by using a least-squares method to fit an exponential distribution through the measured PSD. This was repeated for all times in a flight. Relationships can then be established for $N_{O S}$ vs ice water content (IWC) and atmospheric temperature.

Our numerical modeling effort previously employed a relationship for Nos that is a function of temperature only. ${ }^{10,17}$ Recall that our snow category represents the larger ice particles (excluding graupel and hail), and assumes an inverse exponential size distribution, whereas our cloud ice category only represents the smaller ice particles with diameters less than about $200 \mathrm{um}$. Using combined data measured from each day of the NASA deployment (Table 1) and binning according to temperature, a new relationship was determined for Nos that is a function of both temperature and snow water content, $M s$ :

$$
\begin{gathered}
\log _{10}(\mathrm{Nos})= \\
\text { for } T \mathrm{Tc}>-55^{\circ} \mathrm{C} \text { and } \mathrm{Ms}<4 \mathrm{~g} \mathrm{~m}^{-3}
\end{gathered}
$$

where: Nos has units of $m^{-4}, M s$ has units of $g m^{-3}$, and $T c$ is temperature of the environment in centigrade. The relationship was fitted from the flight data as shown in Fig. A1, and produces a larger intercept value for either colder temperatures or increasing snow water content. A higher intercept value translates into a distribution with overall smaller particles, lower radar reflectivity factor, and slightly slower fall velocity. Other parameterized microphysical processes are affected by the assumption for Nos; these include sublimation or deposition of snow particles, and other growth processes.

Note that when $M s \rightarrow 0$, the above relationship asymptotes to a relationship suggested by Woods et al, ${ }^{71}$ who derived their relationship from analyzing ice particles in wintertime precipitation occurring in the Pacific Northwest. Based on all ice particles, they found the following relationship for No:

$$
\log _{10}\left(N_{o}\right)=7.53-0.0207 T c
$$

Since their measured ice water contents ranged between 0.03 and $0.30 \mathrm{~g} \mathrm{~m}^{-3}$, it would have been difficult for them to detect any dependency of $N o$ on ice water content.

As a further check to the validity Eq. (A-1), we compare the observed short-range RRF with the value estimated from the measured IWC, using the assumption of an inverse exponential size distribution with Eq. (1) as:

$$
Z_{S}\left[m^{6} / m^{3}\right]=3.90 \times 10^{8} M_{s}^{1.75} N_{o s}{ }^{-0.75}
$$

where the above assumes melted spherical particles and accounts for the differences in radar dielectric constants for ice and water.

The comparisons are shown in Fig. A1, and illustrates the lack of correlation of radar reflectivity with snow water concentration, for values of snow water greater than about $1 \mathrm{~g} \mathrm{~m}^{-3}$.

American Institute of Aeronautics and Astronautics 

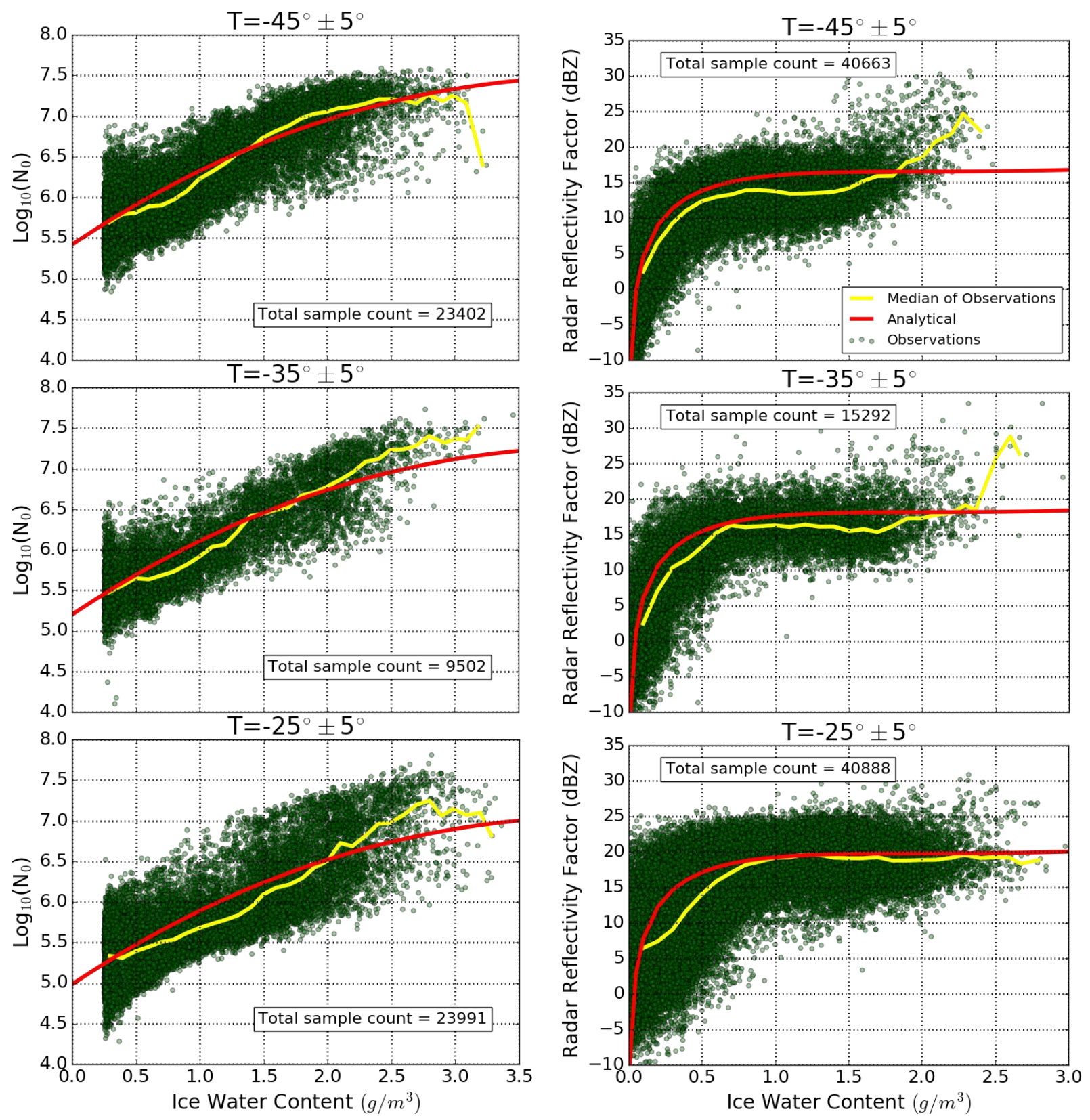

Figure A1. Ice particle distribution intercept, $N_{o s}$, $v s$ ice water content for three temperature ranges. Data points derived from PSD distributions measured during all 2015 DC-8 Flight Campaign flights (i.e. Table 1). Blue curve represents medium value. Red curve is fit using Eq. (A-1).

Figure A2. Radar reflectivity factor $v s$ ice water content for three temperature ranges. Data points of close-range RRF measured during all 2015 DC-8 Flight Campaign flights (i.e. Table 1). Blue curve represents medium value. Red curve using Eqs. (A-3) and (A-1). 


\section{Acknowledgments}

This research is sponsored by the Advanced Air Transport Technology Project of NASA's Advanced Air Vehicles Program. The authors would like to acknowledge the contributing organizations that enabled the Florida HIWC Radar Flight Campaign: the FAA Aviation Research Division and Aviation Weather Division, the NASA Aviation Safety Program, the Boeing Company, Met Analytics, Science Engineering Associates, Environment Canada, the National Center for Atmospheric Research, Honeywell, and Rockwell Collins. The authors also would like to thank Tom Ratvasky (NASA Glenn Research Center), and Walter Strapp (Met Analytics) for their programmatic, technical, and operational support; and the NASA Langley Satellite Group for providing satellite images. In addition, thanks to Alexei Korolev (Environment and Climate Change Canada) for processing the PSD data from raw data collected during the flight test. The numerical simulations were conducted using the Pleiades high-performance supercomputer cluster of the NASA Advanced Supercomputing Division.

\section{References}

\footnotetext{
${ }^{1}$ Mason, J.G., Strapp, J.W., and Chow, P., “The Ice Particle Threat to Engines in Flight,” AIAA 2006-206, doi: 10.2514/6.2006$\underline{206}$.

${ }^{2}$ Mason, J.G., and Grzych, M., "The Challenges Identifying Weather Associated with Jet Engine Ice Crystal Icing," SAE International 2011-38-0094, doi:10.4271/2011-38-0094.

${ }^{3}$ Bravin, M., Strapp, J.W., and Mason, J., "An Investigation into Location and Convective Lifecycle Trends in an Ice Crystal Icing Engine Event Database,” SAE International 2015-01-2130, doi:10.4271/2015-01-2130.

${ }^{4}$ Addy, H.E., Jr., and Veres, J.P., “An Overview of NASA Engine Ice-Crystal Icing," SAE International, 2011-38-0017, doi: $10.4271 / 2011-38-0017$.

${ }^{5}$ Grandin, A., Merle, J-M., Weber, M., Strapp, J.W., Protat, A., and King, P. “AIRBUS Flight Tests in High Ice Water Content Regions," AIAA 2014-2753, doi:10.2514/6.2014-2753.

${ }^{6}$ Protat, A., and Rauniyar, S., Kumar, V.V., and Strapp, J.W., "Optimizing the Probability of Flying in High Ice Water Content
} Conditions in the Tropics Using a Regional-Scale Climatology of Convective Cell Properties," Journal of Applied Meteorology and Climatology, Vol. 53, November 2014, pp. 2438-2456, doi:10.1175/jamc-d-14-0002.1.

${ }^{7}$ Dezitter, F., Grandin, A., Brenguier, J.L., Hervy, F., Schlager, H., Villedieu, P., and Zalamansky, G., "HAIC (High Altitude Ice Crystals)," AIAA 2013-2674, doi:10.2514/6.2013-2674.

${ }^{8}$ Houze, R.A., Jr., "Mesoscale Convective Systems," Review of Geophysics, Vol. 42, RG4003, 2004, pp. 1-43, doi:10.1029/2004RG000150.

${ }^{9}$ Grzych, M., Tritz, T., Mason, J., Bravin, M., and Sharpsten, A. "Studies of Cloud Characteristics Related to Jet Engine Ice Crystal Icing Utilizing Infrared Satellite Imager,” SAE International 2015-01-2086, doi:10.4271/2015-01-2086.

${ }^{10}$ Proctor, F.H., and Switzer, G.F., "Numerical Simulation of HIWC Conditions with the Terminal Area Simulation System," AIAA-2016-4203, doi:10.2514/6.2016-4203.

${ }^{11}$ Houze, R.A., Jr., Cloud Dynamics, Ed Academic Press, 1993, 573 pp., doi:10.1002/qi.49712051918.

${ }^{12}$ FAA, “Turbojet, Turboprop, and Turbofan Engine Induction System Icing and Ice Ingestion,” February 2004, Advisory Circular 20-147, doi:10.4271/510198.

${ }^{13}$ Davison, C.R., Strapp, J.W., Lilie, L., Ratvasky, T.P., Dumont, C., "Isokinetic TWC Evaporator Probe: Calculations and Systemic Uncertainty Analysis,” AIAA 2016-4060, doi:10.2514/6.2016-4060.

${ }^{14}$ Strapp, J.W., Lilie, L.E., Ratvasky, T.P., Davison, C., and Dumont, C., "Isokinetic TWC Evaporator Probe: Development of the IKP2 and Performance Testing for the HAIC-HIWC Darwin 2014 and Cayenne-2015 Field Campaigns," AIAA 2016-4059, doi: $10.2514 / 6.2016-4059$.

${ }^{15}$ Lilie, L.E., Sivo, C.P., and Bouley, D.B., "Description and Results for a Simple Ice Crystal Detection System for Airborne Applications," AIAA 2016-4058, doi:10.2514/6.2016-4058

${ }^{16}$ Crum, T.D., and Alberty, R.L, "The WSR-88D and the WSR-88D Operational Support Facility," Bulletin of the American Meteorological Society, Vol. 74, No. 9, 1993, pp. 1669-1688, doi:10.1175/1520-0477, doi:10.1175/1520-0477(1993)074<1669:TWATWO>2.0CO;2.

${ }^{17}$ Proctor, F.H., "The Terminal Area Simulation System, Volume I: Theoretical Formulation,” April 1987, NASA CR-4046.

${ }^{18}$ Proctor, F.H., "Numerical Simulation of Wake Vortices Measured During the Idaho Falls and Memphis Field Programs," $14^{\text {th }}$ AIAA Applied Aerodynamic Conference, Proceedings, Part II, June 1996, AIAA 96-2496-CP, pp. 943-960, doi: $10.2514 / 6.1996-2496$.

${ }^{19}$ Proctor, F.H., "Interaction of Aircraft Wakes from Laterally Spaced Aircraft," AIAA 2009-0343, doi:10.2514/6.2009-343.

${ }^{20}$ Proctor, F.H., "Numerical Simulations of an Isolated Microburst. Part I: Dynamics and Structure," Journal of the. Atmospheric Sciences, Vol. 45, pp. 3137-3160, doi:10.1175/1520-0469(1988)045<3137:nsoaim>2.0.co;2.

${ }^{21}$ Proctor, F.H., and Bowles, R.L., "Three-Dimensional Simulation of the Denver 11 July 1988 Microburst-Producing Storm," Meteorology and Atmospheric Physics, Vol. 49, 1992, pp. 107-124, doi:10.1007/bf01025403.

${ }^{22}$ Proctor, F.H., 1989, "Numerical Simulations of an Isolated Microburst. Part II: Sensitivity Experiments," Journal of the Atmospheric Sciences, Vol. 46, 15 July 1989, pp. 2143-2165, doi:10.1175/1520-0469(1989)046<2143:nsoaim>2.0.co;2.

American Institute of Aeronautics and Astronautics 
${ }^{23}$ Proctor, F.H., Bracalente, E.M., Harrah, S.D., Switzer, G.F., and Britt, C.L., "Simulation of the 1994 Charlotte Microburst with Look-Ahead Windshear Radar," Preprints, $27^{\text {th }}$ Conference on Radar Meteorology, American Meteorological Society, October 1995, pp. 530-532, Paper-10B-7.

${ }^{24}$ Proctor, F.H., Hamilton, D.W., and Bowles, R.L., "Numerical Study of a Convective Turbulence Encounter," AIAA 20020944, doi:10.2514/6.2002-944.

${ }^{25}$ Ahmad, N.N., and Proctor, F.H., "Large Eddy Simulations of Severe Convection Induced Turbulence," AIAA 2011-3201, doi: $10.2514 / 6.2011-3201$.

${ }^{26}$ Han, J., Lin, Y.-L., Schowalter, D.G., Arya, S.P., and Proctor, F.H., "Large Eddy Simulation of Aircraft Wake Vortices within Homogeneous Turbulence: Crow Instability,” AIAA Journal, Vol. 38, February 2000, pp 292-300, doi:10.2514/2.956.

${ }^{27}$ Proctor, F. 2004 report H., Hamilton, D.W., and Han, J., "Wake Vortex Transport and Decay in Ground Effect: Vortex Linking with the Ground," AIAA 2000-0757, doi:10.2514/6.2000-757.

${ }^{28}$ Proctor, F.H, Hamilton, D.W., Rutishauser, D.K., and Switzer, G.F., "Meteorology and Wake Vortex Influence on American Airlines FL-587 Accident," April 2004, NASA TM-2004-213018.

${ }^{29}$ Proctor, F.H., "Numerical Study of a Long-Lived, Isolated Wake Vortex in Ground Effect," AIAA 2014-2469, doi: $10.2514 / 6.2014-2469$.

${ }^{30}$ Schowalter, D.G., DeCroix, D.S., Lin, Y.-L., Arya, S.P., and Kaplan, M.L., "Planetary Boundary Layer Simulation using TASS," April 1996, NASA CR-198325.

${ }^{31}$ DeCroix, D.S., Lin, Y.-L., and Schowalter, D.G., "Cellular Convection Embedded in the Convective Planetary Boundary Layer," Journal of Wind Engineering and Industrial Aerodynamics, Vol. 67, pp. 387-401, doi:10.1016/s0167-6105(97)00088-3.

${ }^{32}$ Ding, F., Arya, S.P., Lin, Y.-L., "Large-Eddy Simulation of the Atmospheric Boundary Layer Using a New Subgrid-Scale Model, II. Weakly and Moderately Stable Cases,” Environmental Fluid Mechanics, Vol. 1, 2001, pp. 49-69,

doi:10.1023/a:1011543715591.

${ }^{33}$ Proctor, F.H., Ahmad, N.N., and Limon Duparcmeur, F.M., "Numerical Simulation of a Tornado Generating Supercell," AIAA 3012-0557, doi:10.2514/6.2012-557.

${ }^{34}$ Proctor, F.H., "The Terminal Area Simulation System. Volume II: Verification Experiments," April 1987, NASA CR- 4047.

${ }^{35}$ Vreman, A.W., "An Eddy-Viscosity Subgrid-Scale Model for Turbulent Shear Flow: Algebraic Theory and Applications," Physics of Fluids, Vol. 16, October 2004, pp. 3670-3681, doi:10.1063/1.1785131.

${ }^{36}$ Proctor, F.H., and Han, J., "Numerical Study of Wake Vortex Interaction with Ground Using the Terminal Area Simulation System," AIAA 99-0754, doi:10.2514/6.1999-754.

${ }^{37}$ Switzer, G. and Proctor, F., “Terminal Area Simulation System User's Guide - Version 10.0,” January 2014, NASA TM2014-218150.

${ }^{38}$ Proctor, F.H., "Numerical Simulation of Wake Vortices Measured During the Idaho Falls and Memphis Field Programs," $14^{\text {th }}$ AIAA Applied Aerodynamic Conference, Proceedings, Part II, June 1996, AIAA 96-2496-CP, pp. 943-960, doi: $10.2514 / 6.1996-2496$.

${ }^{39}$ Leonard, B.P., MacVean, M.K., and Lock, A.P., "The Flux-Integral Method for Multidimensional Convection and Diffusion," Applied Mathematical Modeling, Vol. 19, 1995, pp. 333-342, doi:10.1016/0307-904x(95)00017-e.

${ }^{40}$ van Leer, B., "Towards the Ultimate Conservative Difference Scheme: V, A Second-Order Sequel to Godunov's Method," Journal of Computational Physics, Vol. 32, 1979, pp. 101-136, doi:10.1016/0021-9991(79)90145-1.

${ }^{41}$ Ahmad, N.N., and Proctor, F.H., "Advection of Microphysical Scalars in Terminal Area Simulation System (TASS),” AIAA 2011-1004, doi:10.2514/6.2011-1004.

${ }^{42}$ Klemp, J.B., and Wilhelmson, R., "The Simulation of Three-Dimensional Convective Storm Dynamics," Journal of the Atmospheric Sciences, Vol. 35, June 1978, pp. 1070-1096, doi:10.1175/1520-0469(1978)035<1070:tsotdc>2.0.co;2.

${ }^{43}$ Wang, C.Y., "Exact Solutions of the Navier-Stokes Equations - The Generalized Beltrami Flows, Review and Extension," Acta Mechanica, Vol 81, 1990, pp. 69-74, doi:10.1007/bf01174556.

${ }^{44}$ Switzer, G.F., "Validation Tests of TASS for Application to 3-D Vortex Simulations," October 1996, NASA CR-4756.

${ }^{45}$ Bull, J.R., and Jameson, A., "Simulation of the Compressible Taylor Green Vortex using High-Order Flux Reconstruction Schemes," AIAA 2014-3210, doi:10.2514/6.2014-3210.

${ }^{46}$ Chapelier, J-B., Plata, M.D.L.L., and Renac, F., "Inviscid and Viscous Simulations of the Taylor-Green Vortex Using a Modal Discontinuous Galerkin Approach,” AIAA 2012-3073, doi:10.2514/6.2012-3073.

${ }^{47}$ DeBonis, J.R., "Solutions of the Taylor-Green Vortex Problem Using High-Resolution Explicit Finite Difference Methods," AIAA 2013-0382, doi:10.2514/6.2013-382.

${ }^{48}$ Ahmad, N., and Proctor, F.H., "Simulation of Benchmark Cases with the Terminal Area Simulation System," AIAA 2011 1005, doi:10.2514/6.2011-1005.

${ }^{49}$ Lin, Y-L., Farley, R.D., and Orville, H.D., "Bulk Parameterizations of the Snow Field in a Cloud Model," Journal of Climate and Applied. Meteorology, Vol. 32, 1983, pp. 1065-1092, doi:10.1175/1520-0450(1983)022<1065:bpotsf>2.0.co;2.

${ }^{50}$ Rutledge, S.A., and Hobbs, P.V., "The Mesoscale and Microscale Structure and Organization of Clouds and Precipitation. VIII: A Model for the "Seeder-Feeder" Process in Frontal Rainbands," Journal of the Atmospheric Sciences, Vol. 40, May, 1983, pp. 1185-1206, doi:10.1175/1520-0469(1983)040<1185:tmamsa>2.0.co;2.

American Institute of Aeronautics and Astronautics 
${ }^{51}$ Berry, E.X., and Reinhardt, R.E., “An Analysis of Cloud Drop Growth by Collection. Part I: Double Distributions,” Journal of the. Atmospheric Sciences, Vol. 31, October 1974, pp. 1814-1824, doi:10.1175/1520-0469(1974)031<1814:aaocdg>2.0.co;2.

${ }^{52}$ Berry, E.X., and Reinhardt, R.E., "An Analysis of Cloud Drop Growth by Collection. Part II: Single Initial Distributions," Journal of the. Atmospheric Sciences, Vol. 31, October 1974, pp. 1825-1831, doi:10.1175/1520-0469(1974)031<1825:aaocdg>2.0.co;2.

${ }^{53}$ Proctor, F.H., 1989, "Numerical Simulations of an Isolated Microburst. Part II: Sensitivity Experiments," Journal of the Atmospheric Sciences, Vol. 46, 15 July 1989, pp. 2143-2165, doi:10.1175/1520-0469(1989)046<2143:nsoaim>2.0.co;2.

${ }^{54}$ Sekhon, R.S., and Srivastava, R.C., "Doppler Radar Observations of Drop-Size Distributions in a Thunderstorm," Journal of the Atmospheric Sciences, Vol. 28, September 1971, pp. 983-994, doi:10.1175/1520-0469(1971)028<0983:droods>2.0.co;2.

${ }^{55}$ Musil, D.J., "Computer Modeling of Hailstone Growth in Feeder Clouds," Journal of the Atmospheric Sciences, Vol. 27, 1970, pp.474-482, doi:10.1175/1520-0469(1970)027<0474:cmohgi>2.0.co;2.

${ }^{56}$ Smith, P.L., Jr., Myers, C.G., and Orville, H.D., "Radar Reflectivity Factor Calculations in Numerical Cloud Models using Bulk Parameterizations of Precipitation," Journal of Applied Meteorology, Vol. 14, September 1975, pp. 1156-1165, doi:10.1175/1520-0450(1975)014\%3C1156:rrfcin\%3E2.0.co;2.

${ }^{57}$ Rogers, R.R., A Short Course in Cloud Physics, Pergamon Press, 1976, 227 pp., doi:10.1007/bf00876948.

${ }^{58}$ Blanchard, D.O., "Assessing the Vertical Distribution of Convective Available Potential Energy," Weather and Forecasting, Vol. 13, No. 3, September 1998, pp. 870-877, doi:10.1175/1520-0434(1998)013<0870:atvdoc>2.0.co;2.

${ }^{59}$ Proctor, F.H., 1985, "Three Dimensional Simulation of the 2 August CCOPE Hailstorm with the Terminal Areas Simulation System," Report of the International Cloud Modelling Workshop/Conference, World Meteorological Organization, WMP Report No.8, Technical Document WMO/TD-139, September 1986, pp. 227-240.

${ }^{60}$ Knight, C.A., "The Cooperative Convective Precipitation Experiment (CCOPE), 18 May -7 August 1981," Bulletin of the American Meteorological Society, Vol. 63, No. 4, April 1982, pp. 386-398, doi: 10.1175/1520-0477(1982)063<0386:tccpem>2.0.co;2.

${ }^{61}$ Wade, C.G., "A Preliminary Study of an Intense Thunderstorm Which Moved Across the CCCOPE Research Network in Southeastern Montana," Preprints, $9^{\text {th }}$ Conference on Forecasting and Analysis," American Meteorological Society, 1982, pp. 388395.

${ }^{62}$ Miller, L.J., "The CCOPE Hailstorm of 2 August 1981,” Report of the International Cloud Modelling Workshop/Conference, World Meteorological Organization, WMP Report No.8, Technical Document WMO/TD-139, September 1986, pp.193-198.

${ }^{63}$ Miller, L.J., Tuttle, J.D., and Knight, C.A., "Airflow and Hail Growth in a Severe Northern High Plains Supercell, “ Journal of the Atmospheric Sciences, Vol 45, No. 4 1988, pp. 736, doi:10.1175/1520-0469(1988)045<0736:aahgia>2.0.co;2.

${ }^{64}$ Wang, P.K., "Moisture Plumes Above Thunderstorm Anvils and their Contributions to Cross-Tropopause Transport of Water Vapor in Midlatitudes,' Journal of Geophysical Research, Vol. 108, No. D6, 4194, 2003, doi:10.1029/2002jd002581.

${ }^{65}$ Musil, D.J., Heymsfield, A.J., and Smith, P.L., "Microphysical Characteristics of a Well-Developed Weak Echo Region in a High Plains Supercell Thunderstorm,” Journal of Climate and Applied Meteorology, Vol. 25, July 1986, pp. 1037-1051, doi:10.1175/1520-0450(1986)025<1037:mcoawd>2.0.co;2.

${ }^{66}$ Weisman, M.L., Klemp, J., Miller, L.J., "Modeling and Doppler Analysis of the CCOPE August 2 Supercell Storm, Preprints, $13^{\text {th }}$ Conference on Severe Local Storms, American Meteorology Society, 1983, pp. 223.226.

${ }^{67}$ Davies-Jones, R.P., Burgess, D., and Foster, M., "Test of Helicity as a Tornado Forecast Parameter," Preprints, 16th Conf. on Severe Local Storms, American Meteorological Society, 1990, pp. 588-592.

${ }^{68}$ Brooks, H.E., Doswell, C.A., III, and Cooper, J., "On the Environments of Tornadic and Nontornadic Mesocyclones," Weather Forecasting, Vol. 9, December 1994, pp. 606-618, doi:10.1175/1520-0434(1994)009<0606:oteota>2.0.co;2.

${ }^{69}$ Korolev, A., and Sussman, B., "A Technique for Habit Classification of Cloud Particles," Journal of Atmospheric and Oceanic Technology, Vol. 17, August 2000, pp. 1048-1057, doi:10.1175/1520-0426(2000)017<1048:atfhco>2.0.co;2.

${ }^{70}$ Marshall, J.S., and Palmer, W.M., "The Distribution of Rain-Drops with Size," Journal of the Atmospheric Sciences, Vol. 5, 1948, pp. 179-207, doi:10.1175/1520-0469(1948)005<0165:tdorws>2.0.co;2.

${ }^{71}$ Woods, C.P., Stoelinga, M.T., and Locatelli, J.D., "Size Spectra of Snow Particles Measured in Wintertime Precipitation in the Pacific Northwest,” Journal of the Atmospheric Sciences, Vol. 65, January 2008, pp. 189- 205, doi:10.1175/2007jas2243.1.

American Institute of Aeronautics and Astronautics 